\title{
LAS PUNTAS DE PROYECTIL EN "MANDORLA" DE INCA CUEVA 7: CARACTERIZACIÓN TIPOLÓGICA E HISTORIA DE VIDA (PUNA DE JUJUY, ARGENTINA)
}

Carlos Aschero, Salomón Hocsman ${ }^{1}$ y Norma Ratto ${ }^{2}$

\section{* Introducción}

Resumen

Se analizan las puntas de proyectil en "mandorla" recuperadas en un depósito intencional de múltiples artefactos del sitio Inca Cueva 7 (Puna de Jujuy, Argentina), datado ca. 4000 años AP. El análisis se centra en su diseño y en sus alternativas de uso, entendiendo por éstas el modo en que pudieron utilizarse ambos extremos de cada punta. Para mostrar las características de este diseño se incluye la comparación con un conjunto de piezas en "mandorla" del sitio Camarones 14 (costa del norte de Chile) y se realizan diversas pruebas estadísticas. Por último, considerando las características de tres ejemplares recuperados del sitio argentino, se discuten sus ventajas en maximizar el rendimiento de las puntas y de los intermediarios de astil.

Palabras claves: puntas de proyectil - puntas en "mandorla" - tipología cazadores recolectores - Arcaico - Puna de Jujuy.

Abstract

Mandorla projectile points recovered in a ca. 4000 years BP intentional deposit of artifacts from the Inca Cueva 7 site (Puna of Jujuy, Argentina), are analyzed. They are studied in terms of their design and use alternatives, because it could be used one extreme or the other, turning the points at the foreshaft; besides these artifacts could be the result of resharpening of blades and/or shafted parts. We include a comparison between mandorla projectile points from Inca Cueva 7 site and mandorla artifacts from Camarones 14 site (Northern Chile). Several statistical tests are performed. Then, the benefits to maximize the performance of foreshaft, are discussed on the basis of the characteristics of three specimens recovered from the Argentinian site studied.

Key words: projectile points - mandorla projectile points - typology hunter-gatherers - Archaic - Puna of Jujuy - South Central Andes.

Recibido: diciembre 2010. Aceptado: marzo 2011.
Una serie de trabajos recientes ha dado cuenta de la variabilidad sincrónica y diacrónica de los diseños de artefactos líticos tallados en los Andes Centro Sur durante el Holoceno, especialmente de las puntas de proyectil (Núñez 1992; Martínez 2003, 2007; De Souza 2004a, 2004b, 2006; Klink y Aldenderfer 2005; Núñez et al. 2005; Hocsman 2006, 2010; Ratto 2006). En este trabajo se abordan, justamente, las puntas de proyectil de Inca Cueva 7, uno de los sitios emblemáticos de fines del Holoceno Medio de la Puna argentina, situado en la quebrada homónima en el borde oriental de la Puna de Jujuy.

Recurrentemente se ha planteado la importancia del papel de los diseños lanceolados en la Puna argentina (Muscio 2001 Ms; Cardillo 2005, entre otros), donde Inca Cueva 7 tiene un lugar destacado. Sin embargo, la revisión que dio origen a este trabajo plantea que las puntas de proyectil predominantes en este sitio pueden diferenciarse del diseño lanceolado, constituyendo un grupo distinto que denominamos específicamente en "mandorla" - con bordes biconvexos en norma frontal-, lo que trae aparejadas una serie de consideraciones de interés sobre la variabilidad macro regional de las puntas de proyectil en la subárea Circumpuneña.

Se analizan aquí diferentes aspectos tecno-tipológicos de un conjunto de puntas de proyectil de Inca Cueva 7, al que se incorporaron piezas de Camarones 14 (costa norte de Chile) -correspondientes a la morfología que los colegas chilenos denominan "bipuntas" o "doble puntas"-,

\footnotetext{
1. CONICET, Universidad Nacional de Tucumán. San Martín 1545 (4000), San Miguel de Tucumán, ARGENTINA. Email: ascherocarlos@ yahoo.com.ar; Email shypb@arnet.com.ar

2 Universidad de Buenos Aires. Moreno 350 (1091), Buenos Aires, Argentina. Email: nratto@yahoo.com.ar
} 
definiendo y discutiendo la noción de diseño en "mandorla" y confrontándolo a la designación "bipunta". Se aborda, además, el análisis de los indicadores de situaciones de reversión de ápices por bases - y viceversa- en el marco de procesos de mantenimiento y como parte de estrategias de extensión de la vida útil de estas puntas y de sus intermediarios. Tres de estos últimos, del contexto de Inca Cueva 7, permitieron evaluar alternativas de maximización de estas piezas elaboradas sobre cañas macizas procedentes de las selvas de montaña.

La aproximación metodológica para abordar las puntas de proyectil se basó en la propuesta morfológico-descriptiva macroscópica de Aschero (1975 Ms, 1983 Ms) utilizando el programa SSPS 15.0 para realizar la estadística descriptiva e inferencial de los casos que componen la muestra. Debe advertirse que solo se consideraron aquellas piezas con valores de largo, ancho y espesor confiable, ya sea por constituir piezas enteras $y / o$ por presentar fracturas mínimas que permitían inferir el valor de la variable afectada.

\section{* Los sitios ARqueológicos}

Inca Cueva 7 (ICc7) fue excavado en la década de 1970 $y$, posteriormente en los años 1990, se ampliaron los trabajos (Aguerre et al. 1973, 1975; Aschero y Yacobaccio 1998-99). El sitio se localiza en el margen oriental del curso medio de la quebrada de Inca Cueva, en el extremo suroeste del departamento Humahuaca, Jujuy, Argentina (Figura 1). Se trata de una oquedad natural formada en las areniscas rojas de la Formación Pirgua, con 3,20 m de ancho, $3 \mathrm{~m}$ de profundidad y 2,30 $\mathrm{m}$ de altura máxima (la que disminuye marcadamente hacia el interior donde alcanza solo $1 \mathrm{~m}$ ). Se emplaza a $30 \mathrm{~m}$ sobre el nivel de base local y a 3860 m.s.n.m, con orientación sur y con un talud de fuerte pendiente (Aguerre et al. 1973).

Para los objetivos de este trabajo interesan las capas 2 y 3. En la primera se recuperó una importante variedad de artefactos y ecofactos sobre una amplia variedad de materias primas, que constituían un depósito intencionalmente configurado con haces de gramíneas (paja) y

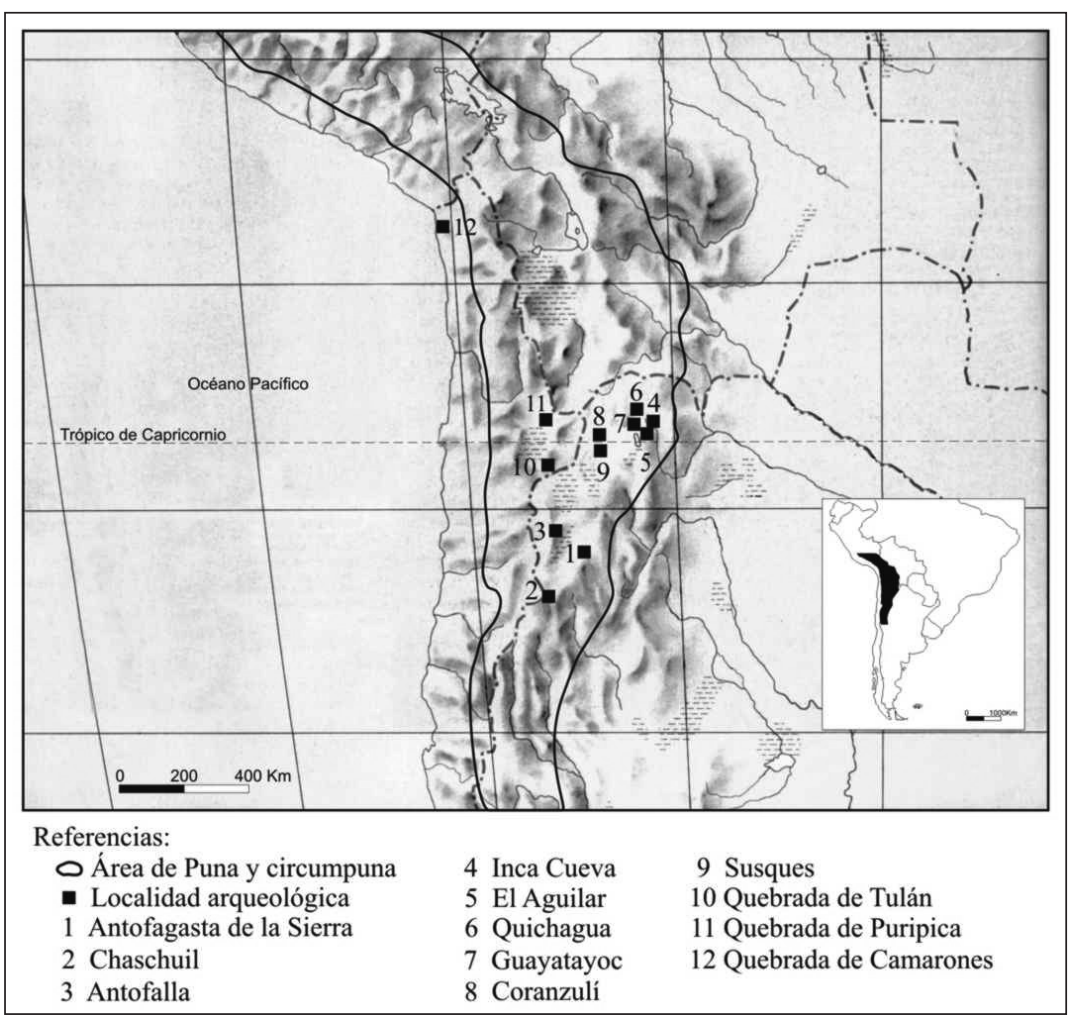

Figura 1. Mapa con la ubicación de las localidades arqueológicas mencionadas en el texto. 
bloques de cuarcitas transportadas a la oquedad (Aguerre et al. 1973, 1975). La capa 3 representa diferentes episodios de ocupación y cuenta con artefactos y ecofactos de diversa índole. Así, se identificó un lente de excremento de camélido interestratificado en la matriz. Este lente superaba los límites originales de la acumulación de roca que contenía el depósito con paja y artefactos, hacia el frente de la cueva. Por encima y por debajo del lente de guano (capas $3 a$ y 3 b, respectivamente) se registraron artefactos y ecofactos, dando cuenta de ocupaciones previas a la capa 2 (Aschero y Yacobaccio 1998-99).

Las dataciones para la capa 2 son $4080 \pm 80$ años AP (Aguerre et al. 1975) y para la capa 3b $4030 \pm 80$ años AP (Aschero y Yacobaccio 1998-99).

Por su parte, el sitio Camarones 14 (Cam-14) se localiza en la desembocadura del valle homónimo en la costa del norte de Chile (ver Figura 1), y está constituido por ocupaciones a cielo abierto, con una estratigrafía relativamente compleja con fogones, morteros y distribuciones de vestigios conformando pisos de ocupación y áreas de acumulación de desechos. En un sector del sitio se individualizó un área funeraria con inhumaciones tempranas conocidas como Chinchorro. Las ocupaciones se dataron entre 7500 y 6500 años AP (Niemeyer y Schiappacasse 1977; Schiappacasse y Niemeyer 1984). El conjunto analizado se encuentra actualmente depositado en el Museo Nacional de Historia Natural, en Santiago, y las observaciones y mediciones fueron realizadas por Aschero en 1990, con autorización de Hans Niemeyer, entonces director de dicho Museo, y la atenta orientación de Virgilio Schiappacasse en su laboratorio.

\section{* Las muestras de puntas de proyectil}

La muestra de puntas de proyectil de ICc7 consiste en 22 piezas en "mandorla" que incluyen 18 piezas obtenidas en 1972 (Aguerre et al. 1973), tres en 1993 (Aschero y Yacobaccio 1998-99) y una en 2004 (Tabla 1). El conjunto completo de puntas de proyectil publicado en 1973 proviene de la capa 2. Respecto a las del año 1993, dos fueron recuperadas en la capa 3 y y la restante en la capa 2. Finalmente, la hallada en el año 2004 fue encontrada por Aschero en la superficie del talud inmediato a la cueva. Cabe destacar que en este trabajo se consideran solo los diseños en "mandorla" y los trasformados vinculados a éstos, habiendo otros diseños - de presencia minoritaria- que no son considerados.

En el caso de Cam-14 se analizaron 11 puntas de proyectil en "mandorla". El conjunto lítico estudiado por Aschero provenía de las excavaciones de 1977, de las unidades G-L y del testigo intermedio, comprendiendo el total de los lotes 13047, 13044 y 13048 (Tabla 2).

\section{* Consideraciones metodológicas}

\section{Clasificación según forma geométrica del contorno}

Las piezas consideradas fueron clasificadas originalmente por Aguerre y colaboradores (1973) como puntas de proyectil foliáceas. Éste era un término relativamente extendido en los Andes Centro Sur y que continúa hasta la actualidad; con él se alude a formas que podían asimilarse a hojas vegetales o bien, para referirse a piezas con trabajo bifacial o cubriente en una sola de las caras (Brézillon 1983), conjugándose a menudo ambas posibilidades. Cabe señalar que bajo el término foliáceo se incluyen diferentes formas como, por ejemplo, hojas de laurel, hojas de sauce, lanceoladas o bipuntas (Cheynier 1955; Demars y Laurent 1992).

Precisamente por esa extrema inclusión que admite la noción de "foliáceo", se propone dejar de utilizar el término para designar formas de puntas de proyectil. Hay que tener en cuenta además, que la denominación "piezas foliáceas" se utilizó para designar instrumentos bifaciales de espesor muy delgado, con lascados profundos y extendidos o parcialmente extendidos; de filo normal, perimetral, con borde regular $y / 0$ irregular y arista sinuosa regular y/o irregular; siendo la sección transversal biconvexa en norma sagital y lateral, pudiendo ser simétrica o asimétrica en norma frontal o sagital (Aschero y Hocsman 2004). De acuerdo a lo dicho, en estas piezas el valor del cociente ancho sobre espesor (índice anchoespesor) es discriminante. Las "piezas foliáceas" se distinguen de los "bifaces" cuando ese cociente es igual o mayor que 5 (Aschero y Hocsman 2004).

Para evitar confusiones proponemos limitar el concepto en cuestión al último sentido señalado y dar cuenta de 


\begin{tabular}{|c|c|c|c|c|c|c|c|c|c|c|c|c|c|c|c|c|c|c|c|c|c|c|c|c|}
\hline 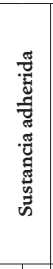 & 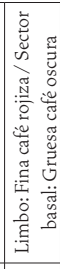 & & z̊ & ż & 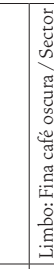 & 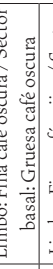 & 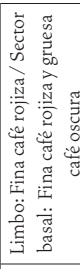 & 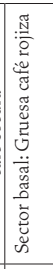 & 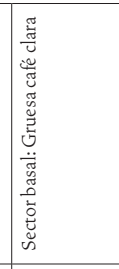 & 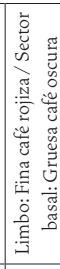 & & 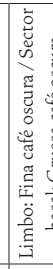 & 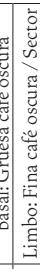 & & & 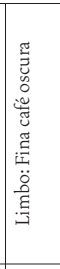 & 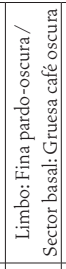 & 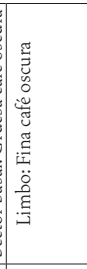 & 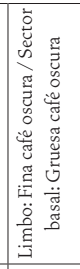 & 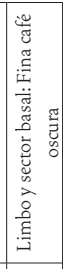 & 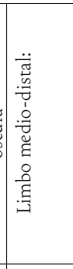 & 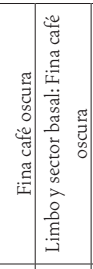 & ? & 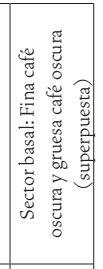 \\
\hline |c: & & z & in & ż & 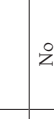 & & is & is & in & is & そ & $\check{z}$ & $\stackrel{8}{z}$ & & 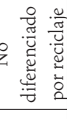 & is & ż & in & z & is & ż & in & in & $\bar{i}$ \\
\hline 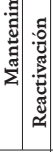 & 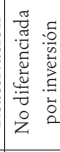 & 音 & 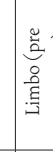 & & 章 & & 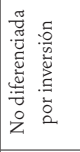 & 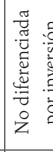 & 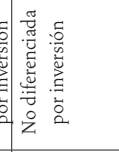 & 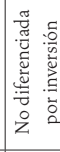 & $\frac{\mathrm{g}}{\frac{\pi}{4}}$ & 总 & है & & 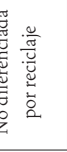 & 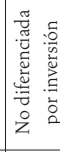 & 产 & 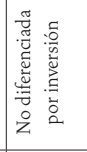 & ฉ & 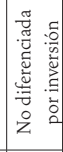 & $\frac{1}{z}$ & 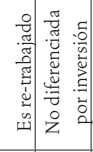 & & th \\
\hline 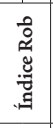 & $\begin{array}{l}\infty \\
\hat{i} \\
i\end{array}$ & $\stackrel{\substack{0 \\
\vec{i}}}{2}$ & $\frac{7}{m}$ & $\stackrel{\partial}{m}$ & 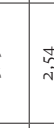 & it & $\underset{\hat{i}}{\hat{i}}$ & $\overline{\hat{m}}$ & ' & $\begin{array}{l}\hat{\tilde{i}} \\
\hat{i}\end{array}$ & $\begin{array}{l}\infty \\
\substack{0 \\
i}\end{array}$ & \begin{tabular}{l}
\multirow{N}{N}{} \\
N
\end{tabular} & ז̂̃ & స્. & $\hat{m}$ & 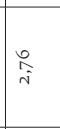 & $\mid \begin{array}{c}\infty \\
\substack{0 \\
j}\end{array}$ & 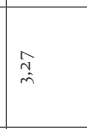 & & 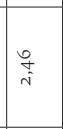 & $\approx$ & $\begin{array}{l}\hat{N} \\
\hat{i}\end{array}$ & $\mid \begin{array}{c}\infty \\
\substack{i \\
i}\end{array}$ & \\
\hline 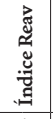 & $O_{0}^{1}$ & $\begin{array}{l}\frac{\pi}{2} \\
0\end{array}$ & $\mid \begin{array}{l}\hat{w} \\
\hat{n} \\
0\end{array}$ & $\mid$\begin{tabular}{l}
0 \\
\multirow{1}{*}{} \\
0
\end{tabular} & $\begin{array}{c}\text { : } \\
\text { o }\end{array}$ & & $\mid$ & $\begin{array}{l}\hat{y} \\
\hat{y}\end{array}$ & ' & $\frac{a}{0}$ & $\vec{n}$ & $\begin{array}{l}0 \\
0 \\
0\end{array}$ & $\frac{9}{0}$ & בֶ. & did $\sigma_{0}^{d}$ & $\begin{array}{l}0 \\
\vdots \\
0 \\
0\end{array}$ & 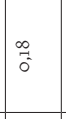 & $\begin{array}{l}\vec{\pi} \\
0\end{array}$ & & $\begin{array}{l}\vec{y} \\
0 \\
0\end{array}$ & 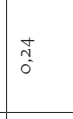 & $\begin{array}{l}\text { Ñ } \\
\text { O. }\end{array}$ & $\begin{array}{l}\vec{A} \\
0\end{array}$ & \\
\hline 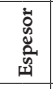 & 尽 & $\begin{array}{l}0 \\
\vdots \\
6\end{array}$ & 尽 & 领 & 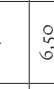 & $\begin{array}{l}0 \\
:\end{array}$ & {$\left[\begin{array}{l}0 \\
\vdots \\
0 \\
0\end{array}\right.$} & $\frac{\circ}{\infty}$ & $\begin{array}{l}\infty \\
\infty \\
0 \\
0\end{array}$ & 淤 & 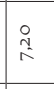 & 足 & 곰 & $\begin{array}{l}: \\
:\end{array}$ & : & $\mid \begin{array}{l}\infty \\
\infty \\
\infty\end{array}$ & @: & 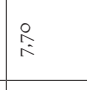 & $\begin{array}{l}0 \\
\infty \\
0 \\
0\end{array}$ & $\frac{9}{0}$ & $\begin{array}{l}0 \\
\vdots \\
0\end{array}$ & \begin{tabular}{l}
0 \\
\multirow{2}{*}{} \\
s.
\end{tabular} & 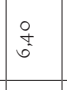 & $\mid \begin{array}{l}0 \\
0 \\
\infty \\
\infty\end{array}$ \\
\hline $\begin{array}{l}8 \\
\stackrel{\sharp}{4} \\
\end{array}$ & 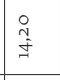 & $\begin{array}{l}\circ \\
\stackrel{8}{5} \\
:\end{array}$ & 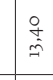 & 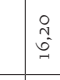 & & $\begin{array}{l}\circ \\
\text { : } \\
\text { İ }\end{array}$ & $\begin{array}{l}0 \\
0 \\
-\pi\end{array}$ & 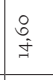 & $\begin{array}{l}\stackrel{2}{a} \\
\text { İ }\end{array}$ & $\stackrel{\circ}{\stackrel{0}{9}}$ & 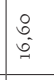 & $\begin{array}{l}\stackrel{0}{\cong} \\
\cong\end{array}$ & 号 & & & $\begin{array}{l}0 \\
\stackrel{0}{\approx} \\
\end{array}$ & ஃ & $\begin{array}{l}\circ \\
\vdots \\
\vdots \\
\vdots\end{array}$ & 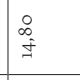 & $\stackrel{\circ}{:}$ & 年 & 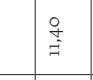 & $\begin{array}{l}\circ \\
\vdots \\
\dot{y}\end{array}$ & 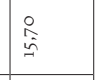 \\
\hline $\begin{array}{l}8 \\
8 \\
5 \\
3\end{array}$ & 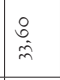 & 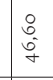 & 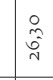 & $\begin{array}{l}\circ \\
\vdots \\
\dot{m} \\
\end{array}$ & 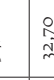 & & $\begin{array}{l}\circ \\
\dot{\vec{m}}\end{array}$ & 要 & 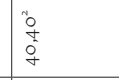 & $\begin{array}{l}: \\
\vdots \\
i \\
m\end{array}$ & 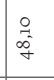 & $\begin{array}{l}\circ \\
\infty \\
\tilde{f}\end{array}$ & $\therefore$ & & & $\begin{array}{l}0 \\
\circ \\
\dot{f} \\
\end{array}$ & 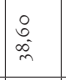 & 吕 & $\begin{array}{l}0 \\
\stackrel{0}{0} \\
m\end{array}$ & $\begin{array}{c}\infty \\
\substack{\infty \\
\infty \\
\text { jud }}\end{array}$ & $\begin{array}{l}0 \\
\therefore \\
i \\
i\end{array}$ & 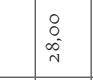 & $\begin{array}{l}\stackrel{2}{2} \\
\stackrel{m}{m}\end{array}$ & 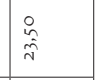 \\
\hline 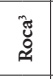 & is & u & $\breve{u}$ & $u$ & u & & 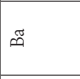 & 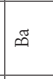 & is & $\breve{u}$ & $u$ & $\breve{u}$ & is & is & $\bar{n}$ & is & ü & u & $\breve{u}$ & $\breve{u}$ & $\breve{y}$ & u & u & in \\
\hline 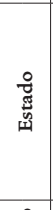 & 㺃 & 嵒 & 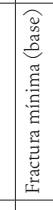 & 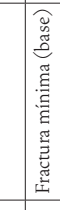 & 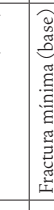 & 总 & 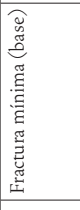 & 䔍 & 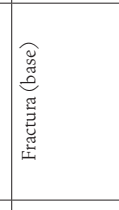 & 㺃 & 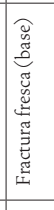 & 㺃 & 惢 & 鞄 & & 㺃 & 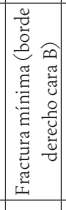 & 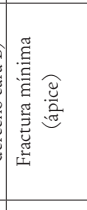 & 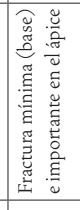 & 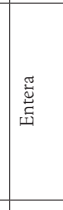 & 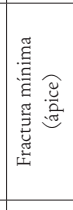 & 㺃 & 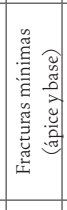 & 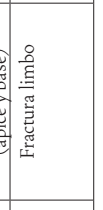 \\
\hline 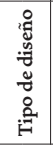 & 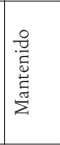 & 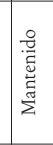 & 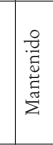 & 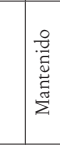 & $\frac{c}{2}$ & & 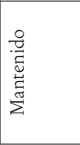 & 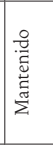 & 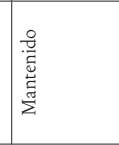 & 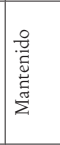 & 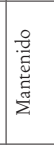 & 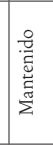 & $\frac{8}{\pi}$ & 莺 & & 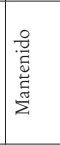 & 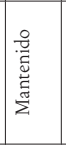 & 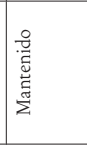 & 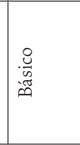 & 总 & 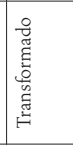 & 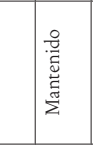 & 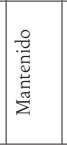 & 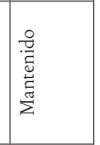 \\
\hline 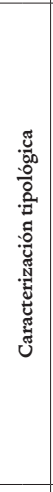 & 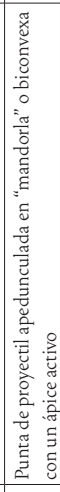 & 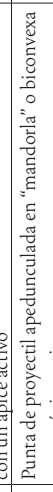 & 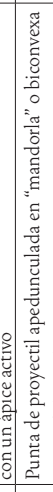 & 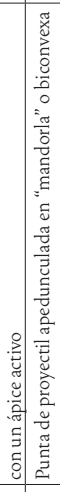 & 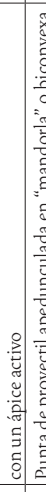 & & 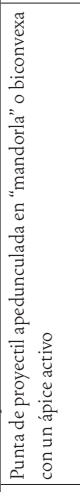 & 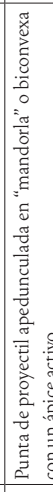 & 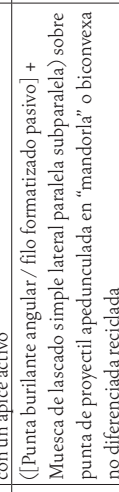 & 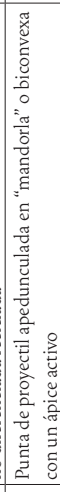 & 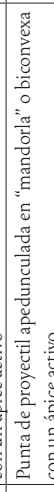 & 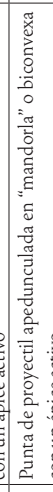 & 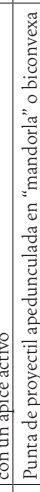 & & 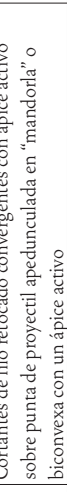 & 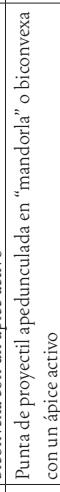 & 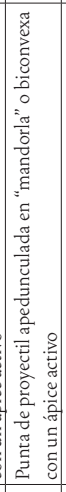 & 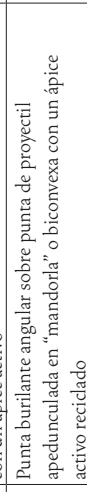 & 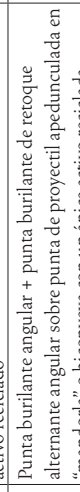 & 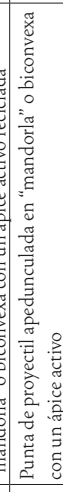 & 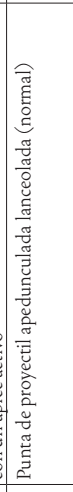 & 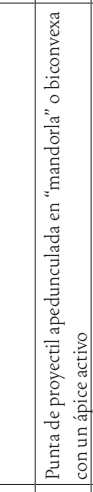 & 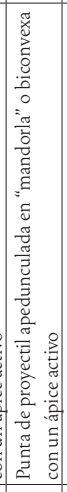 & 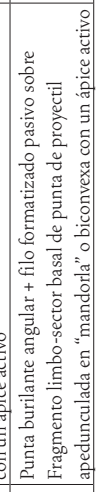 \\
\hline 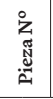 & N & $\tilde{\hat{n}}$ & $\Rightarrow$ & r & $=$ & $\therefore$ & $=$ & $\overrightarrow{\mathrm{j}}$ & $\operatorname{din}^{\prime}$ & m & 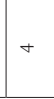 & 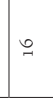 & ᄀ & ¿ & i & $\vec{\lambda}$ & $\stackrel{\infty}{\sim}$ & - & $\cong$ & $\stackrel{N}{=}$ & 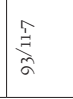 & is & ${ }_{0}^{7}$ & $\underset{\sim}{\infty}$ \\
\hline
\end{tabular}

Tabla 1. Caracterización de las puntas de proyectil analizadas de Inca Cueva 7. ${ }^{1}$ La pieza fue remontada por Martínez (1997). ${ }^{2}$ Largo afectado por reciclaje. ${ }^{3}$ Si: Sílice; Cc: Cuarcita; Ba: Basalto. 


\begin{tabular}{|c|c|c|c|c|c|c|c|c|c|c|c|}
\hline 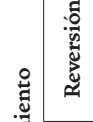 & ż & $\stackrel{0}{z}$ & $\stackrel{z}{z}$ & $\stackrel{0}{z}$ & ż & ż & ż & ż & $\stackrel{\circ}{z}$ & $\stackrel{\circ}{z}$ & z \\
\hline 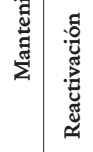 & ż & 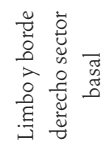 & 竭 & 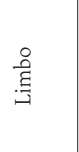 & 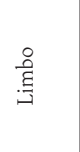 & 遍 & 击 & 煦 & z & 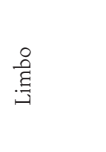 & $\stackrel{\circ}{z}$ \\
\hline 莺 & $\begin{array}{l}0 \\
\text { it }\end{array}$ & $\begin{array}{l}\hat{0} \\
i \\
i\end{array}$ & $\begin{array}{l}7 \\
\text { i }\end{array}$ & $\stackrel{\circ}{m}$ & $\stackrel{+}{+}$ & $\begin{array}{l}\infty \\
\hat{i} \\
\hat{i}\end{array}$ & ' & ' & ' & $\underset{\substack{f \\
j}}{ }$ & ' \\
\hline 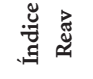 & $0^{t}$ & $\stackrel{\infty}{0^{-}}$ & $\overrightarrow{0}$ & $\begin{array}{l}\vec{n} \\
0\end{array}$ & $\begin{array}{l}0 \\
\stackrel{y}{1} \\
0 \\
0\end{array}$ & $\begin{array}{ll}0 \\
0 \\
0\end{array}$ & ' & & ' & $\overrightarrow{0}$ & \\
\hline 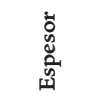 & ફ & $\begin{array}{l}\circ \\
\vdots \\
0\end{array}$ & 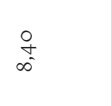 & $\begin{array}{l}0 \\
\vdots \\
0\end{array}$ & $\begin{array}{l}0 \\
\stackrel{0}{0} \\
0\end{array}$ & 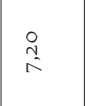 & \begin{tabular}{l}
$\stackrel{0}{0}$ \\
\hdashline
\end{tabular} & $\begin{array}{l}\text { ग̃ } \\
\text { a. }\end{array}$ & $\underset{\infty}{\infty}$ & 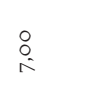 & $\begin{array}{l}0 \\
\vdots \\
\infty\end{array}$ \\
\hline 辛 & $\stackrel{\circ}{\circ}$ & $\begin{array}{l}\circ \\
\infty \\
\dot{J}\end{array}$ & $\begin{array}{l}\circ \\
\vdots \\
\dot{y}\end{array}$ & $\begin{array}{l}8 \\
\stackrel{1}{4}\end{array}$ & $\begin{array}{l}0 \\
i n \\
\end{array}$ & 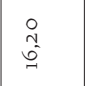 & $\begin{array}{l}0 \\
\stackrel{0}{9} \\
g\end{array}$ & 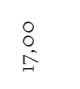 & $\begin{array}{l}0 \\
\stackrel{0}{0} \\
\underline{0}\end{array}$ & $\begin{array}{l}\circ \\
\dot{f}\end{array}$ & $\begin{array}{l}8 \\
\stackrel{1}{\sim}\end{array}$ \\
\hline 总 & $\begin{array}{l}0 \\
8 \\
i \\
i\end{array}$ & $\begin{array}{l}0 \\
\infty \\
\dot{q}\end{array}$ & 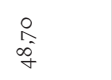 & $\begin{array}{l}0 \\
\hat{i} \\
\dot{y}\end{array}$ & $\begin{array}{l}0 \\
\vdots \\
\dot{\alpha}\end{array}$ & $\begin{array}{l}0 \\
\stackrel{2}{y} \\
y \\
y\end{array}$ & $\begin{array}{l}0 \\
\stackrel{5}{+} \\
\dot{y}\end{array}$ & 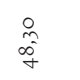 & $\begin{array}{l}\stackrel{\circ}{f} \\
\stackrel{f}{f}\end{array}$ & $\begin{array}{l}\stackrel{0}{0} \\
\stackrel{0}{q}\end{array}$ & $\begin{array}{l}\stackrel{o}{0} \\
\dot{0} \\
\dot{q}\end{array}$ \\
\hline "ृّ & $\bar{i}$ & $\overrightarrow{i s}$ & $\overrightarrow{i n}$ & $\overrightarrow{i n}$ & $\overrightarrow{i n}$ & $\overrightarrow{i s}$ & $\overrightarrow{i n}$ & $\overrightarrow{i s}$ & $\overrightarrow{i n}$ & $\overrightarrow{i n}$ & is \\
\hline 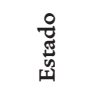 & 焉 & 营 & 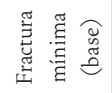 & 营 & 㺃 & 离 & 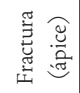 & 惌 & 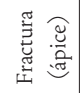 & 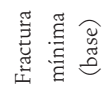 & 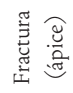 \\
\hline 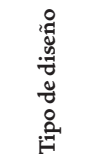 & 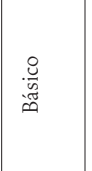 & 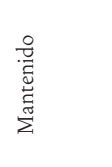 & 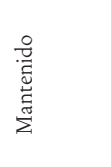 & 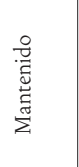 & 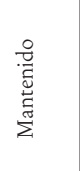 & 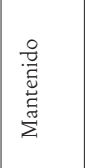 & 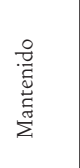 & 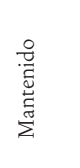 & 总 & 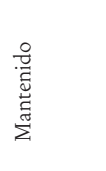 & 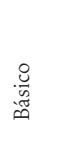 \\
\hline 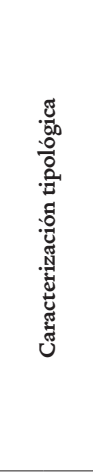 & 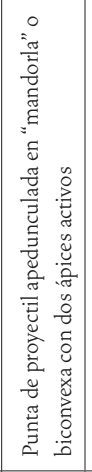 & 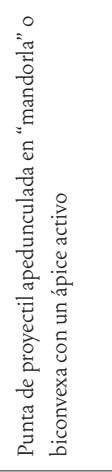 & 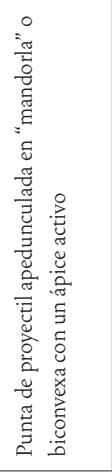 & 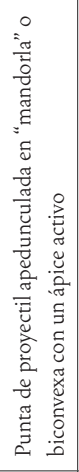 & 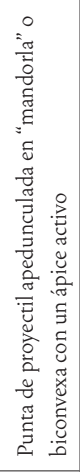 & 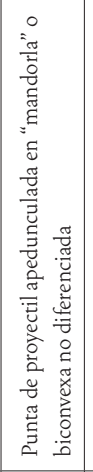 & 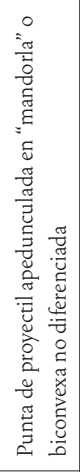 & 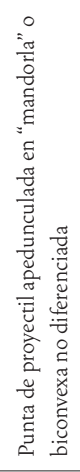 & 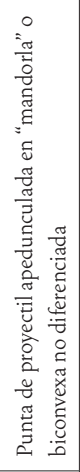 & 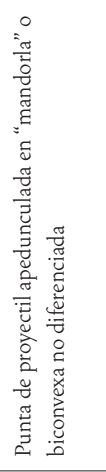 & 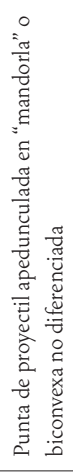 \\
\hline & $\begin{array}{l}\text { f } \\
\text { o } \\
\text { t }\end{array}$ & $\begin{array}{l}\vec{O} \\
\stackrel{\sim}{0}\end{array}$ & $\begin{array}{l}\hat{N} \\
\stackrel{\sim}{\sim}\end{array}$ & $\begin{array}{l}\hat{o} \\
0 \\
0\end{array}$ & \begin{tabular}{l}
0 \\
0 \\
0 \\
\hdashline
\end{tabular} & 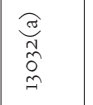 & $\begin{array}{l}\tilde{O} \\
0 \\
0 \\
0\end{array}$ & $\begin{array}{l}\widehat{O} \\
\tilde{N} \\
\tilde{O} \\
\tilde{n}\end{array}$ & 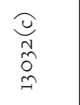 & 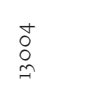 & $\begin{array}{l}\stackrel{0}{0} \\
\stackrel{\sim}{*}\end{array}$ \\
\hline
\end{tabular}

Tabla 2. Caracterización de las puntas de proyectil analizadas de Camarones $14 .{ }^{1}$ Si: Sílice 


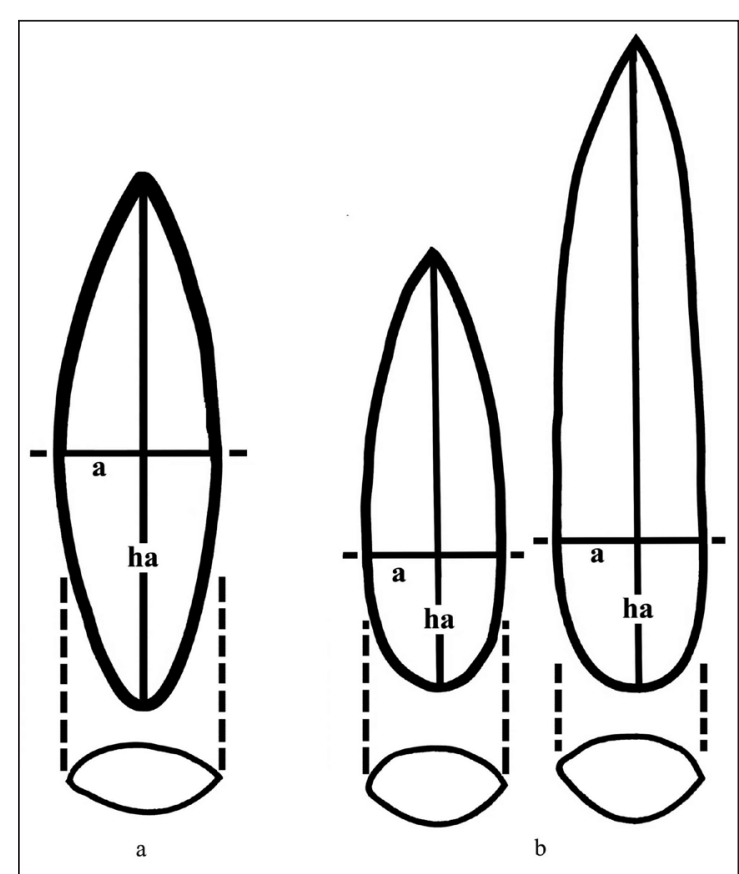

Figura 2. Forma geométrica del contorno. a) Diseño en "mandorla"; b) Diseño "lanceolado".

la morfología de las puntas de proyectil en función de las variables "forma geométrica del contorno" (Aschero 1983), involucrando la localización del ancho y espesor máximos sobre el eje longitudinal de la pieza. Utilizando estas variables es posible separar los diseños "lanceolados" de aquellos en "mandorla".

Dado que este último no fue descrito por Aschero en 1975 y tampoco en 1983, presentamos aquí una caracterización, realizando además una comparación con la forma "lanceolada", que sí fue previamente definida (Aschero $1975 \mathrm{Ms}$ ).

Los diseños en "mandorla" remiten a una figura geométrica en forma de almendra, pero simétrica en norma frontal, determinada por dos semiarcos convergentes. Dicha denominación surge de las figuras usadas en los tímpanos de las catedrales románicas para enmarcar la imagen central de la liturgia católica. Las piezas en "mandorla" pueden describirse en norma frontal como formas de extremo distal y proximal con ambas puntas activas o bien, una activa (aguzada) y otra roma, en las que, siendo a el ancho máximo de la pieza, e el eje morfológico y ha el extremo basal, a se sitúa a $4 / 8$ de $e$, siendo ha mayor que a (Figura 2a). Es decir, el ancho máximo de la pieza se ubica en el centro. En norma lateral esto se repite y esta misma posición de a corresponde a la ubicación del espesor máximo de la pieza.

Las "mandorlas" corresponden a lo que Bordes denomina bifaces "naviformes", de aspecto fusiforme (en forma de huso). Este autor los describe como "alargados, puntiagudos en sus dos extremos, en forma de casco de navío" (Bordes 1961, traducción de Luis Orquera) y distingue dos variedades: típicos y á talon, refiriendo este último a un sector basal de pequeño tamaño, que no culmina en punta. Brezillón (1983) realiza un comentario pertinente a esta variante "nabiforme", señalando que difícilmente se encuadra en la definición dada por Bordes. Si bien esto es cierto, también lo es el hecho de que esta morfología da cuenta de una opción en la cual la forma se asemejaría a la de un barco con la popa trunca.

Ahora bien, siguiendo los comentarios de Brezillón (1983) sobre datos de Bordes (1961), las piezas en "mandorla" se definirían por poseer una altura de ensanchamiento menor a 1.75 , dada por el cociente entre $L$ y $a$, donde $L$ es el largo y a la altura al ancho máximo desde el talón; una proporción $L / m$, mayor a 1.5, donde m es el ancho máximo; lados convexos y sector basal puntiagudo, al que se agregan aquí bases convexas o rectas.

Otras clasificaciones dan cuenta de este tipo de piezas, empleando distintas denominaciones. Así, por ejemplo, Orquera y Piana (1986) las denominan puntas biacuminadas dentro de las piezas sin pedúnculo con limbo centro-expandido o limbo largo o muy largo. En ambos casos, refieren a artefactos de base acuminada con lados convexos.

Klink y Aldenderfer (2005) remiten a una bipunta foliácea que tiene una base puntiaguda más que convexa, con una configuración del sector basal que implica una contracción o convergencia de los bordes. Por otra parte, Lavallée y colaboradores (1995) señalan que su característica morfológica distintiva es una base de bordes convergentes (puntiaguda) o ligeramente trunca, y definen dos variedades: a) de bordes convexos, y b) de bordes angulosos, con punto de inflexión. La forma general de estas puntas es, según la forma de la base, romboidal o pentagonal. Estas últimas, siguiendo los criterios de for- 
ma geométrica del contorno, no corresponderían a piezas en "mandorla", por lo que la primera variante sería el único caso representativo. Dichas piezas fueron definidas como bipuntas por presentar el ancho máximo a mitad del largo total. Podría tratarse de piezas con importante mantenimiento del limbo y, por tanto, de diseños transformados. Lo mismo se apreciaría en los tipos $2 \mathrm{~A}, 4 \mathrm{D}$ y 5 A en Rick (1980), donde las piezas en "mandorla" serían los tipos 5 B y $6 \mathrm{~B}$.

Finalmente, Aschero (1983 Ms) define dos alternativas dentro de las piezas en "mandorla", con claras conexiones con las dos variantes propuestas por Bordes (1961) para los bifaces: a) en "mandorla" o biconvexa con dos ápices activos (bipunta), y b) en "mandorla" o biconvexa con un ápice activo, en la cual se aprecia una diferencia entre dicho ápice activo y un sector basal de extremo redondeado o romo. Cabe destacar que aquí proponemos no emplear el término bipunta, ya que esta noción remite a una diversidad de morfologías, y no solamente a las biconvexas, como por ejemplo, las piezas romboidales.

Por otra parte, los diseños lanceolados refieren a formas de extremo distal romo o aguzado y extremo proximal (o basal) redondeado o convexilíneo, en las que a se sitúa a 5/8 de e, siendo ha mayor que a (Aschero 1975 Ms: 20); dichas proporciones son las que permiten diferenciar consistentemente a este tipo de diseños de los en "mandorla" (Figura 2b).

\section{Reversibilidad del diseño}

En general, las puntas de proyectil se someten a procesos de extensión de su vida útil mediante el mantenimiento. En este último se distingue entre reactivación (rejuvenation) y re-trabajado (reworking). La primera implica renovar un instrumento roto o dañado en un utensilio funcionalmente equivalente (Towner y Warburton 1990); y la segunda involucra retocar un instrumento de forma tal de proveer un borde cortante fresco (afilado), aguzar un ápice o punta o embotar una base (Knetch 1997).

Dentro del mantenimiento se presenta la posibilidad de contar con casos de giro de 180 grados del espécimen, cambiando ápices por bases y viceversa, por efectos del re-trabajado en función de la reparación o reconstrucción del ápice anterior en "base" y de la base en un nuevo "ápi$c e$ ", en la punta de proyectil dañada. Este proceso, denominado "reversión", implica una inversión de la pieza y se concibe en función de las características morfológicas particulares de las puntas de proyectil en "mandorla". Estos diseños son "reversibles" ya que, al presentarse el ancho máximo en la mitad del artefacto, es factible reconfigurar en forma sencilla y rápida ápices y bases.

Se debe tener presente que cuando una pieza cuenta con evidencias de reversión, la modificación del limbo y/o ápice se vincula con este hecho y no con el proceso de reactivación de limbos; es decir, está asociado necesariamente a una modificación de la base. Desafortunadamente, no siempre es posible discriminar el cambio (giro) de sector basal por limbo de reactivaciones posteriores de este último. Por ello, es preciso identificar una situación de relativa sincronía en el cambio de la porción proximal por distal y viceversa, entendiendo que esto ocurre durante la vida útil de la pieza y en probable referencia a un único usuario.

La reactivación alude a situaciones de mantenimiento de ápices, limbos o bases. El caso ideal es observar situaciones de mantenimiento de limbos en los que se aprecia la superposición de distintos eventos de reactivación, pero en ocasiones se puede reactivar el ápice y el limbo ocurriendo previa o posteriormente una modificación de la base. ¿Cómo distinguirlas de la reversión? Para ello es pertinente analizar las fracturas producidas por uso o por otras causas que implican la necesidad del giro de la pieza, lo que es sumamente útil al abordar la muestra considerada. Debe agregarse también, el análisis de las series de lascados a lo largo de bordes completos que posibilitan establecer asociaciones de modificaciones mediando sincronía relativa en el tratamiento de bases y ápices. Por último, la presencia de dentado en los sectores basales es una evidencia indiscutible de reversión. Un punto a remarcar es que en ciertos casos, es difícil establecer la ocurrencia de reactivación por la presencia de reversión posterior, que elimina toda evidencia del primer proceso.

La existencia de diseños reversibles hace necesario distinguir entre diseños "básicos" y "transformados" (Aschero 1988) y diseños "mantenidos" (Martínez 2003). Los diseños "básicos" refieren a piezas que no han sufrido cambios en su morfología por mantenimiento o 
re-trabajado de limbos o bases; mientras que los "transformados", sí han pasado por mantenimiento intensivo o bien, han sufrido algún tipo de daño resultando en una transformación sustancial de la morfología original. A esto se suma la tercera categoría (mantenidos), que define a las piezas que no se corresponden directamente con los tipos transformados ya que los atributos técnicos y tipológicos mantienen proporcionalmente sus diferencias dimensionales y formales. Este término responde al hecho de que las modificaciones a un diseño básico por mantenimiento no siempre generan una pieza tan diferenciada como para considerarla transformada (Martínez 2003). De acuerdo a lo anterior, los diseños reversibles y el proceso de reversión en sí se enmarcarían dentro de los diseños "mantenidos", pese a los cambios radicales en la localización de ápices y bases, ya que las piezas mantienen sus propiedades formales y dimensionales.

\section{$*$ Resultados obtenidos}

\section{Análisis tecno-tipológico de las puntas de proyectil}

La muestra en estudio, como ya fue mencionado, está compuesta por 33 casos procedentes de los sitios ICc7
(22) y Cam-14 (11), que presentan distintos estados de conservación de sus diseños debido a porcentajes de fractura diferenciales (Figura 3). El registro de las variables dimensionales (largo, ancho y espesor) redujo la muestra a 27 casos, dado que por la presencia de fracturas la variable "largo" no pudo ser registrada con suficiente grado de confiabilidad en todos los casos, por lo que la muestra se redujo a 27 casos. No obstante, tomadas en conjunto, las piezas completas o con fracturas irrelevantes alcanzan $81,82 \%$, por lo que la incidencia de fracturas sobre la conformación de los datos es baja.

Las puntas de proyectil analizadas corresponden, con una excepción, a diseños en "mandorla" por presentar dos semiarcos convergentes en norma frontal, con el ancho máximo situado en el centro de la pieza. La excepción es una pieza lanceolada normal procedente de ICc7 $\left(n^{\circ} 11 / 7\right)$, que en realidad es el resultado de procesos de re-trabajado a juzgar por la presencia de una fractura en el sector basal (Figura 4).

Cabe destacar que ha sido posible definir la forma geométrica del contorno de las puntas de proyectil no solo en las piezas fracturadas, sino también en cinco casos que sufrieron reciclaje, debido a que en cuatro de éstos el trabajo

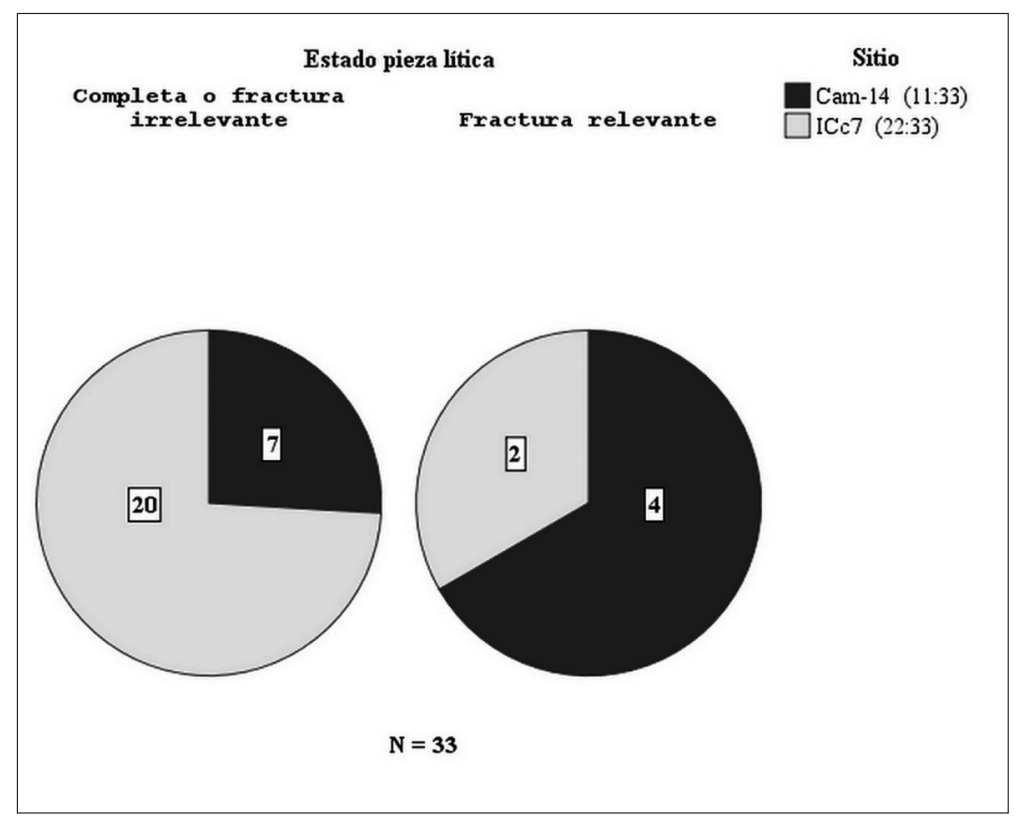

Figura 3. Composición de la muestra de piezas en "mandorla" en función de su procedencia y estado de conservación. 


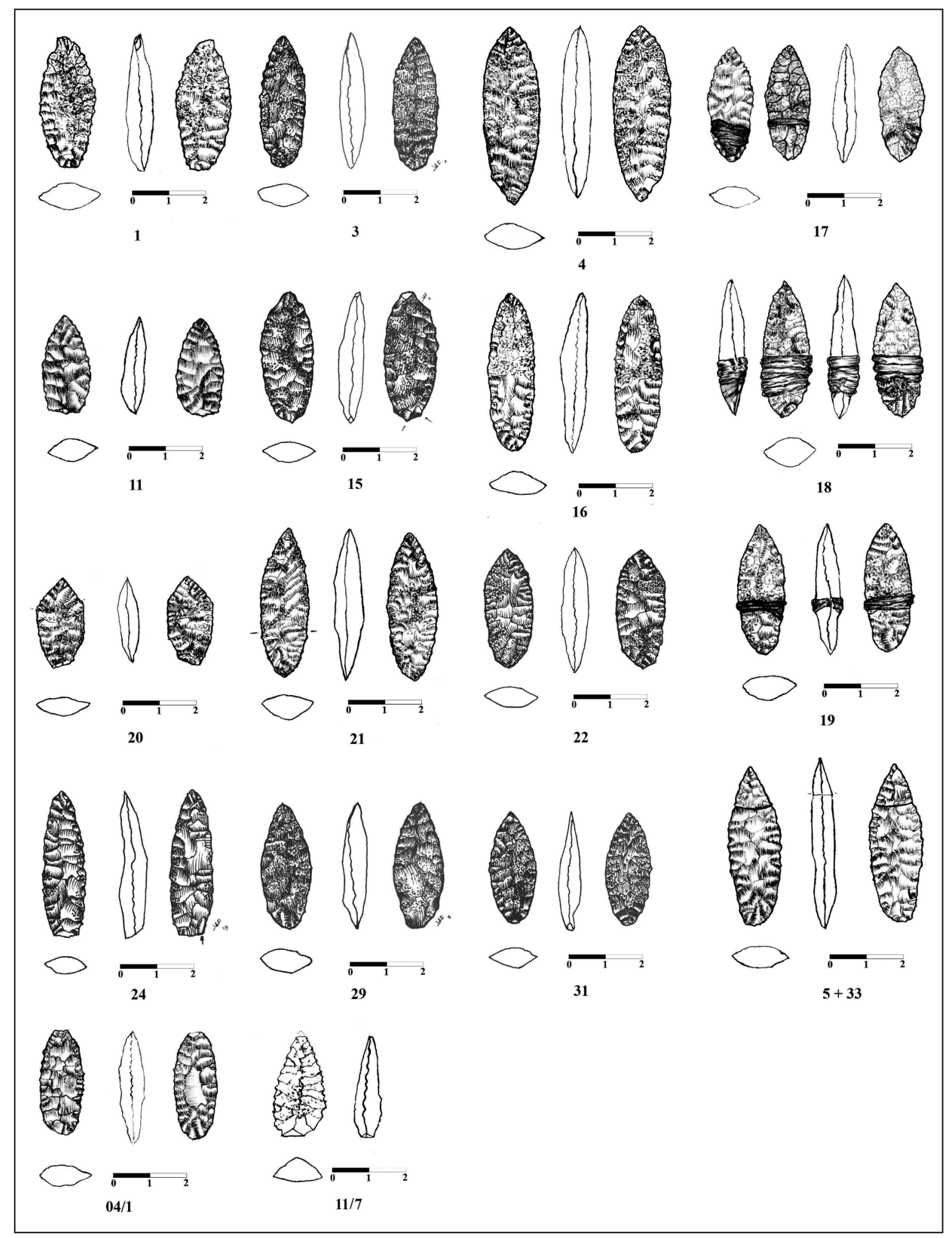

Figura 4. Puntas de proyectil en "mandorla" de Inca Cueva 7. 
es no invasivo y afectó mínimamente la morfología de las puntas de proyectil $\left(n^{\circ} \mathrm{s} 1,24,15\right.$ y 28) y, en uno, pese a sufrir el limbo una intensa modificación, se conservó la morfología de la porción proximal incluyendo la parte media de la pieza ( $\left.\mathrm{n}^{\circ} 20\right)$ (ver Figura 4 ).

Al considerar las variantes de morfologías en "mandorla" propuestas por Aschero (1983 Ms), vemos que en ICc7 se registran 21 casos con un ápice activo; en tanto que el caso restante no es diferenciado porque el sector basal fue reciclado. Por su parte, Cam-14 presenta un caso con los extremos distal y proximal con puntas activas $y$, cuatro casos con un ápice activo (ver Niemeyer y Schiappacasse 1977, lám. 4 y Schiappacasse y Niemeyer 1984: 53, fig. 25). Las otras seis piezas que componen el conjunto analizado de este sitio son no diferenciadas, pues no cuentan con información escrita o gráfica que permita discriminarlas. En función de esto, es posible que el número de puntas de proyectil en "mandorla" con dos ápices activos sea mayor, y de ser así, que esto represente una diferencia entre las piezas de los dos sitios considerados.

Los análisis realizados permitieron identificar diseños básicos, mantenidos y transformados, con la particularidad de que los mantenidos son por reactivación y/o reversión (Figura 5). Es notable la baja proporción de diseños básicos en ICc7 (4,55\%) y la intensa modificación de las piezas, visto esto en función de los diseños mantenidos $(86,36 \%)$ y transformados $(9,10 \%)$. Se destaca que los datos expuestos son consistentes con la intensa utilización de las diversas tecnofacturas que componen el conjunto artefactual de ICc7 (Aguerre et al. 1973; Aschero 2010).

Es pertinente hacer varias observaciones en relación con los transformados. Así, la pieza 93/11-7, de tipo lanceolado, presenta una serie de retoques en la porción basal que tuvieron por objeto reducir una fractura perpendicular al eje morfológico, lo cual queda claramente evidenciado por el hecho de que la pieza muestra una sustancia adherida cubriendo todo el limbo, además de haber sido recortada por los lascados que la reconfiguraron. Por su parte, la pieza $n^{\circ} 20$ presenta una modificación intensiva del limbo (ver Figura 4). Si bien podría catalogarse como una punta de proyectil con pedúnculo esbozado y limbo triangular corto, la imposibilidad de una penetración adecuada por contar con un limbo sumamente estrecho, lleva a considerar que este artefacto fue reciclado en este punto extremo involucrando dos cortantes de filo retocado convergentes con ápice activo, que habrían sido usa-

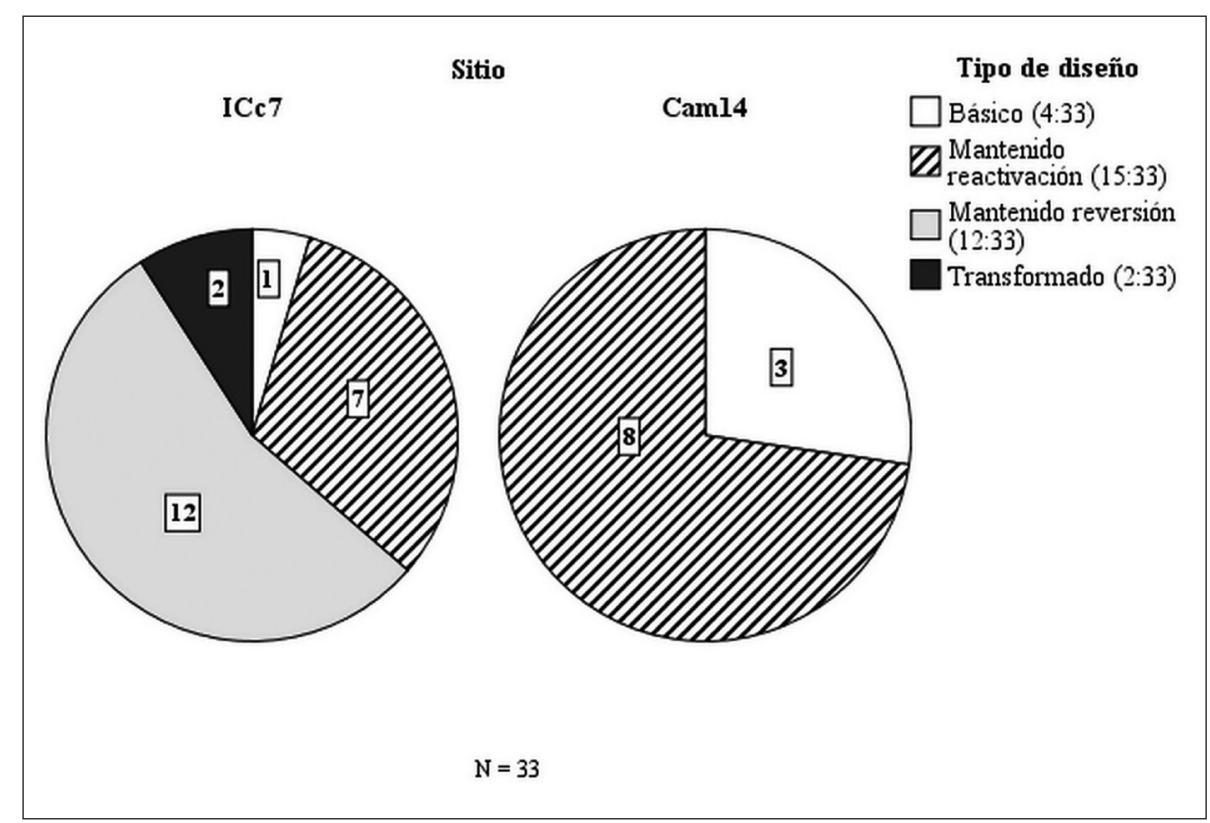

Figura 5. Composición de la muestra en función del tipo de diseño y del sitio de procedencia. 
dos enmangados. La pieza estaba enastilada al momento del mantenimiento, ya que se observa un límite físico impuesto por el enmangue.

En Cam-14 la situación es distinta porque la proporción de diseños básicos es mayor $(27,30 \%)$ y, si bien los diseños mantenidos también son mayoritarios $(72,70 \%)$, no hay piezas transformadas (ver Figura 5).

La reactivación, como era esperable, afecta mayoritariamente a los limbos. Esto es claramente discernible ya que las piezas presentan patrón de lascado escamoso irregular o escalonado (Aschero $1983 \mathrm{Ms}$ ), que se asocian a una asimetría de los bordes del limbo y de los ápices en norma frontal, y a presencia de puntos de inflexión entre los limbos y los sectores basales (p.e., piezas 7, 18,16 y 19) (ver Figura 4). En dos casos (piezas $5+33$ y 4) la reactivación se limita al ápice y porción distal del limbo.

Es necesario destacar que los diseños básicos se caracterizan por presentar dentado en los bordes del limbo, lo que también ocurre en los diseños reactivados, con la salvedad de que a medida que mayor es el mantenimiento, la conservación del dentado es menos frecuente.

Volviendo al patrón de los lascados entre el limbo y el sector basal, dentro de la serie de los escamosos hay diferencias en relación con el número de series y el tipo, tendiendo a tener mayor número y a ser irregulares a escamosos en el primero, y a una menor cantidad y a ser regulares a irregulares en el segundo. Esta situación cambia en algunos casos de reversión, ya que se observa una continuidad en el patrón escamoso escalonado entre el limbo y el sector basal, siendo evidente que ante el cambio de ápice por base y viceversa, la pieza fue desenastilada, y la reversión implicó la modificación de un borde completo o de los dos bordes. En otros casos, la reversión afectó exclusivamente el ápice y porción distal del limbo, así como la base y la porción proximal del sector basal.

Una de las razones principales para revertir una pieza es la ocurrencia de fracturas, sea en ápices o bases. Un caso corresponde a la pieza 11 (ver Figura 4) que presenta pese a poseer una pequeña fractura que afecta parte de la base- una serie de lascados que son muy abruptos y que solo se entienden si se realizaron para rebajar la fractura. De esta forma, dicha base fue previamente parte de un limbo cuyo ápice sufrió una rotura, siendo conveniente reconfigurar la fractura en la base. Esto estaría corroborado en esta pieza por la presencia del patrón escamoso escalonado, típico del mantenimiento, en el sector basal hasta la base misma (p.e., pieza 31), con una fractura en su base que fue rebajada parcialmente -aunque quedó un remanente importante-, y pieza 29, con una fractura en el borde derecho del sector basal que fue modificada para elaborar la base (ver Figura 4).

Otro elemento que permite sostener la ocurrencia de reversión es la presencia de dentado en el sector basal, como un remanente del antiguo limbo. Se cuenta con dos casos, la pieza 21 que comprende ambos bordes del sector basal, y la pieza 1 en cuyo borde izquierdo posee una porción dentada.

Además, se ha podido determinar reversión gracias a un tercer elemento no vinculado con la confección de las piezas mismas, sino con el uso del sistema de arma debido a la excelente conservación de materiales orgánicos en ICc7. Se trata de la observación a simple vista de dos sustancias que recubren las piezas. Una se encuentra en los limbos, es opaca, de color 10 YR 4/2, y está uniformemente distribuida. Se desconoce su naturaleza y/o función, si es que tuvo alguna. La otra, que se presenta en los sectores basales, es brillante, de color 10 YR 2/2, y está irregularmente distribuida, en forma aglutinada. Tiene la apariencia de un adhesivo y muy posiblemente lo sea. ${ }^{3}$ Es destacable que en ciertos casos se aprecie la superposición del adhesivo por sobre la otra sustancia, constituyendo por ende, casos de reversión. Un ejemplo interesante es la pieza 28, en la que - pese a tratarse de un fragmento de punta de proyectil reciclado que comprende básicamente el sector basal- se observan evidencias morfológicas claras de cambio de ápice por base. A esto se suma el hecho de que el fragmento está cubierto por las dos sustancias mencionadas, donde la más gruesa se encuentra por encima de la fina. De esta forma, dicha superposición estaría indicando que la base fue previamente limbo.

Las piezas analizadas (27) fueron manufacturadas en distintas materias primas como basalto, cuarcita y sílice,

\footnotetext{
3 Los estudios composicionales se encuentran en proceso a cargo de la Dra. María del Pilar Babot (CONICET-Universidad Nacional de Tucumán).
} 
dándoles las formas ya mencionadas (Figura 6). Es interesante que no haya una relación estadísticamente significativa entre el tipo de diseño y la materia prima empleada, ya que no se puede rechazar la hipótesis nula del $\mathrm{cm}^{1}$ al nivel de 0,05 de significancia $\left(x^{2}=5,300, \mathrm{gl}=6, \mathrm{p}=0,506\right)$.

La estadística descriptiva de las variables dimensionales (largo, ancho y espesor) se presenta en la Tabla 3.

El Coeficiente de Variación (CV) es una medida de dispersión relativa que representa el número de veces que la desviación típica contiene a la media aritmética y, por lo tanto, cuanto mayor es CV mayor es la dispersión y menor la representatividad de la media (Tabla 4).

La estadística descriptiva señala que la variable "largo" es la que presenta mayor dispersión en la muestra con respecto al ancho y al espesor. El valor de asimetría cercano a cero indica que la variable "largo" tiene una distribución simétrica, mientras que el ancho es asimétrico a la izquierda; lo que significa que la acumulación de valores es inferior a la media y, en el caso del espesor, éste es asimétrico a la derecha, significando acumulación de datos superiores a la media. Por su parte, los valores

\begin{tabular}{|c|c|c|c|c|c|c|c|c|c|}
\hline \multirow{2}{*}{ Medida } & \multirow[t]{2}{*}{$\mathbf{N}$} & \multirow[t]{2}{*}{ Mínimo } & \multirow[t]{2}{*}{ Máximo } & \multirow[t]{2}{*}{ Media } & \multirow[t]{2}{*}{ Desv. Est. } & \multicolumn{2}{|c|}{ Asimetría } & \multicolumn{2}{|c|}{ Curtosis } \\
\hline & & & & & & Estadís. & Estándar & Estadís. & Estándar \\
\hline Largo & 27 & 25,50 & 52,00 & 38,2593 & 8,01231 & 0,098 & 0,448 & $-1,195$ & 0,872 \\
\hline Ancho & 27 & 11,40 & 16,60 & 14,3037 & 1,26840 & $-0,032$ & 0,448 & 0,329 & 0,872 \\
\hline Espesor & 27 & 6,00 & 9,60 & 7,2481 & 1,00589 & 1,145 & 0,448 & 0,543 & 0,872 \\
\hline
\end{tabular}

Tabla 3. Estadística descriptiva.

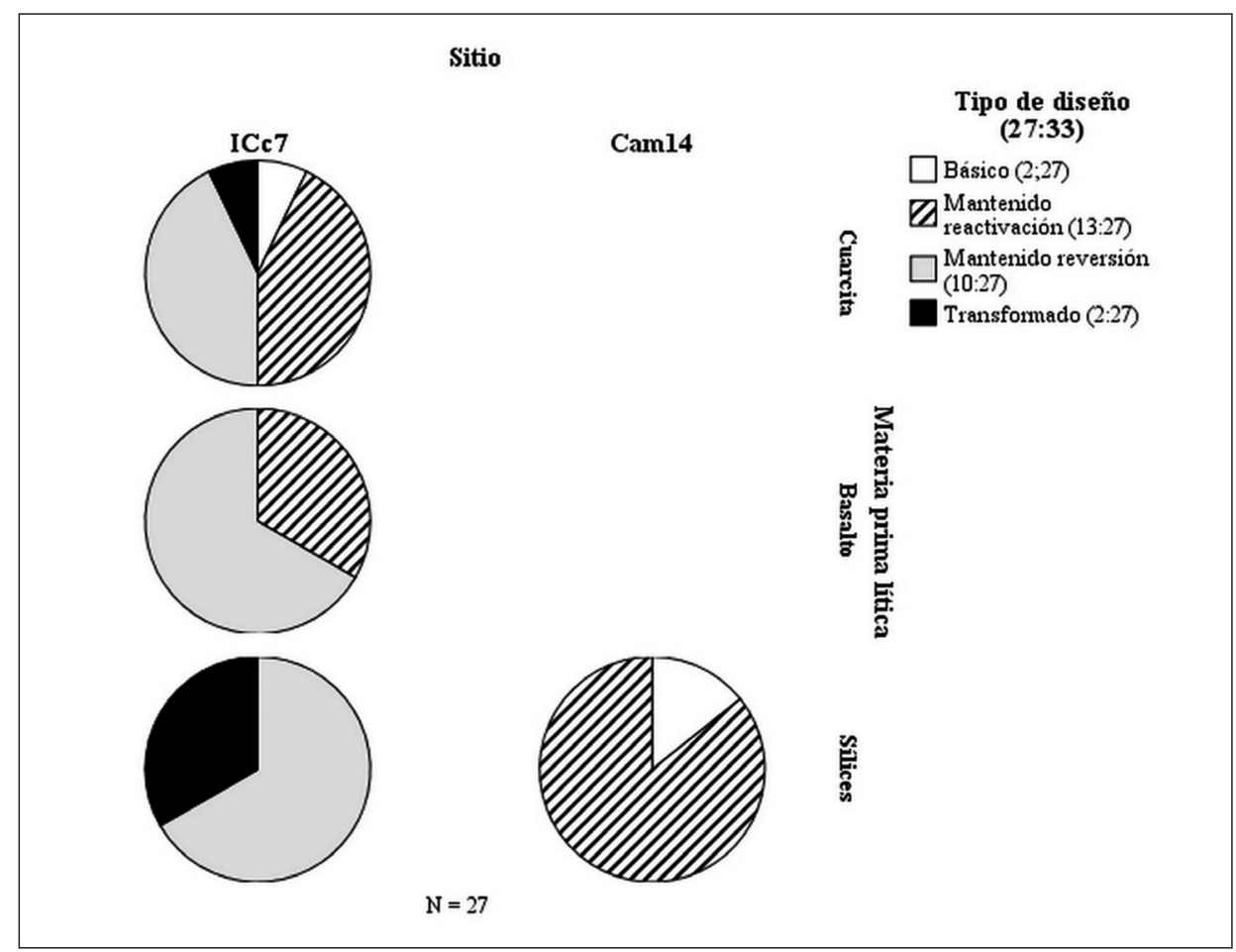

Figura 6. Composición de la muestra en función del tipo de diseño y la materia prima por sitio. 
de curtosis también dan cuenta de diferencias entre las variables, destacándose el largo por sobre el resto. Al respecto, los valores positivos indican una distribución alargada (leptocurtosis), los negativos aplanada (platicurtosis) y los valores cercanos a cero dan cuenta de una distribución normal. Es de aceptación general que valores de asimetría iguales a $\pm 0,5$ y de curtosis $\pm 1,5$ pueden ser considerados como distribuciones norma-

\begin{tabular}{|l|c|c|}
\hline \multicolumn{1}{|c|}{ Variable } & CV & $\% \mathbf{C V}$ \\
\hline Largo & 0,21 & $20,9 \%$ \\
\hline Ancho & 0,09 & $8,8 \%$ \\
\hline Espesor & 0,14 & $13,8 \%$ \\
\hline
\end{tabular}

Tabla 4. Comportamiento de las variables largo, ancho yespesor. les. Esto significa que la variable "espesor" está fuera de esos rangos para la asimetría, debido al comportamiento de los casos 13005 y 13000 de Cam-14. La Figura 7 muestra los valores registrados para las variables dimensionales (largo, ancho y espesor), identificándose los casos de comportamiento extremos. Se observa que hay variación entre dichas variables en función del tipo de diseño registrado $y$, para efectos de visualizar el gráfico, se transforman las variables a logaritmo ( $\mathrm{Fi}$ gura 8). La variable "largo" disminuye a medida que se mantiene o transforma el diseño básico. Por su parte, el ancho en los diseños con mantenimiento por reversión presenta tres casos con valores extremos (1, 93/11-2 y 97/11-8) que proceden de ICc7. El largo disminuye notablemente a medida que avanza el mantenimiento y la transformación, a diferencia del ancho y del espesor, que también ven reducidas sus dimensiones, aunque en

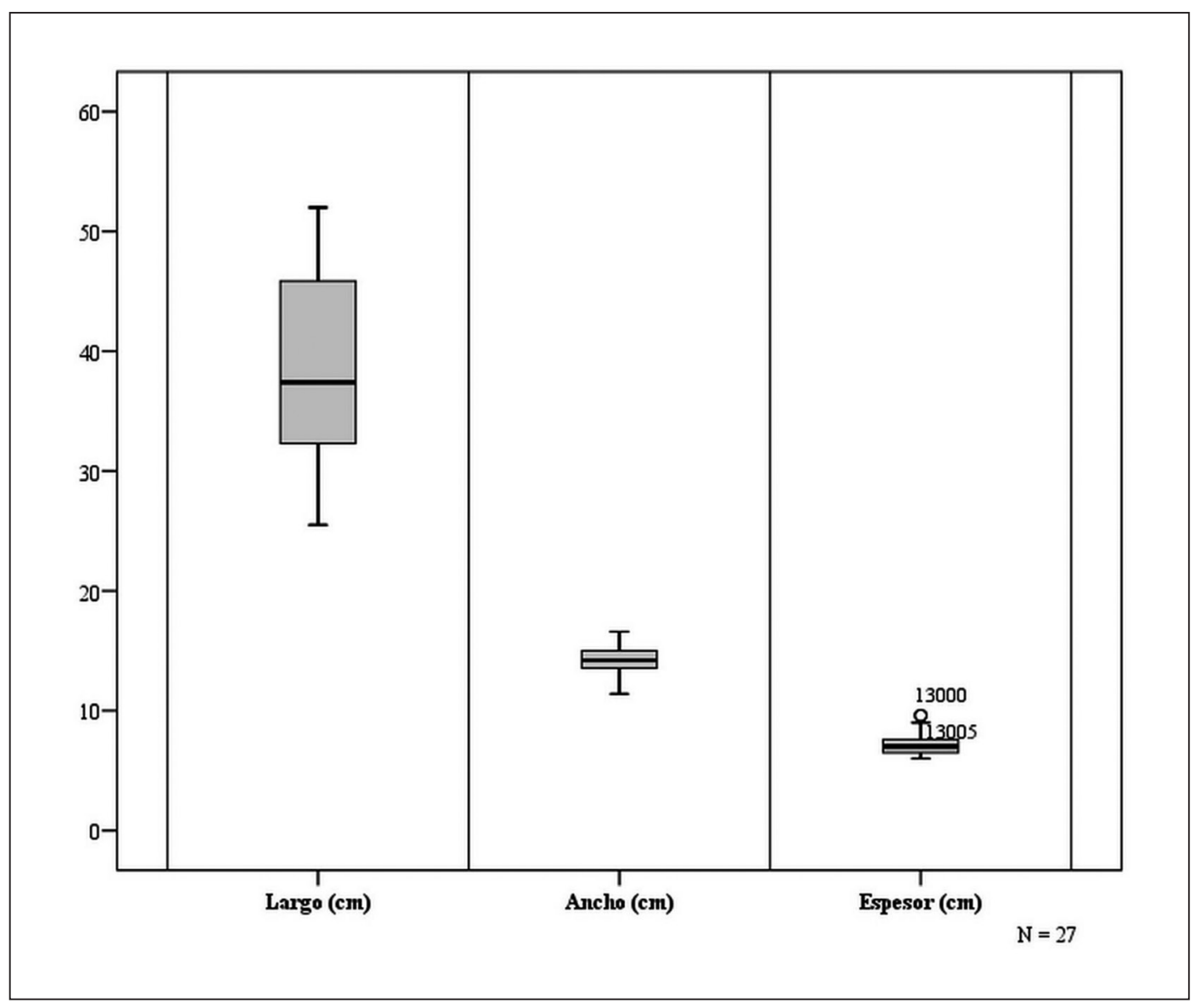

Figura 7. Diagrama de caja que muestra la dispersión de largo, ancho y espesor de las puntas. 
menor cantidad. Esto está claramente vinculado a las características de las "mandorlas", en las que la variable que se reduce a medida que avanza la historia de vida de la pieza es el largo, en tanto el ancho y el espesor prácticamente no sufren modificación por estar ambos máximos en, o próximos a la parte media del artefacto.

Las diferencias en el largo de los diseños llevan a que sea apropiado, en este caso, aplicar los Índices de Reavivamiento y de Robustez empleados por Cardillo (2004), quien los toma de Iriarte (1995) y Scheinsohn (1997), respectivamente. Estos índices son útiles para detectar cambios alométricos en el diseño, vinculados con procesos de mantenimiento.

El Índice de Reavivamiento mide la variación del espesor con respecto al largo. Se fundamenta en que el espesor máximo es poco sensible a la reactivación por ubicarse mayormente próximo al centro de la pieza. Por lo tanto, se espera que la correlación entre el Índice de Reavivamiento y el largo sea baja o negativa. Cuanto mayor valor alcance el índice, las piezas serán proporcionalmente más espesas a medida que disminuyen el largo.

Por su parte, en el Índice de Robustez ([ancho x espesor]/ largo) los valores mayores indicarán formas proporcionalmente más robustas. También se espera que esto ocurra si las actividades de mantenimiento en la reactivación de limbos y ápices redujeron el ancho y el largo de forma proporcional.

En la Tabla 5 se presenta el resultado de la correlación de Pearson entre las variables largo, ancho, espesor, Índice de Reavivamiento e Índice de Robustez.

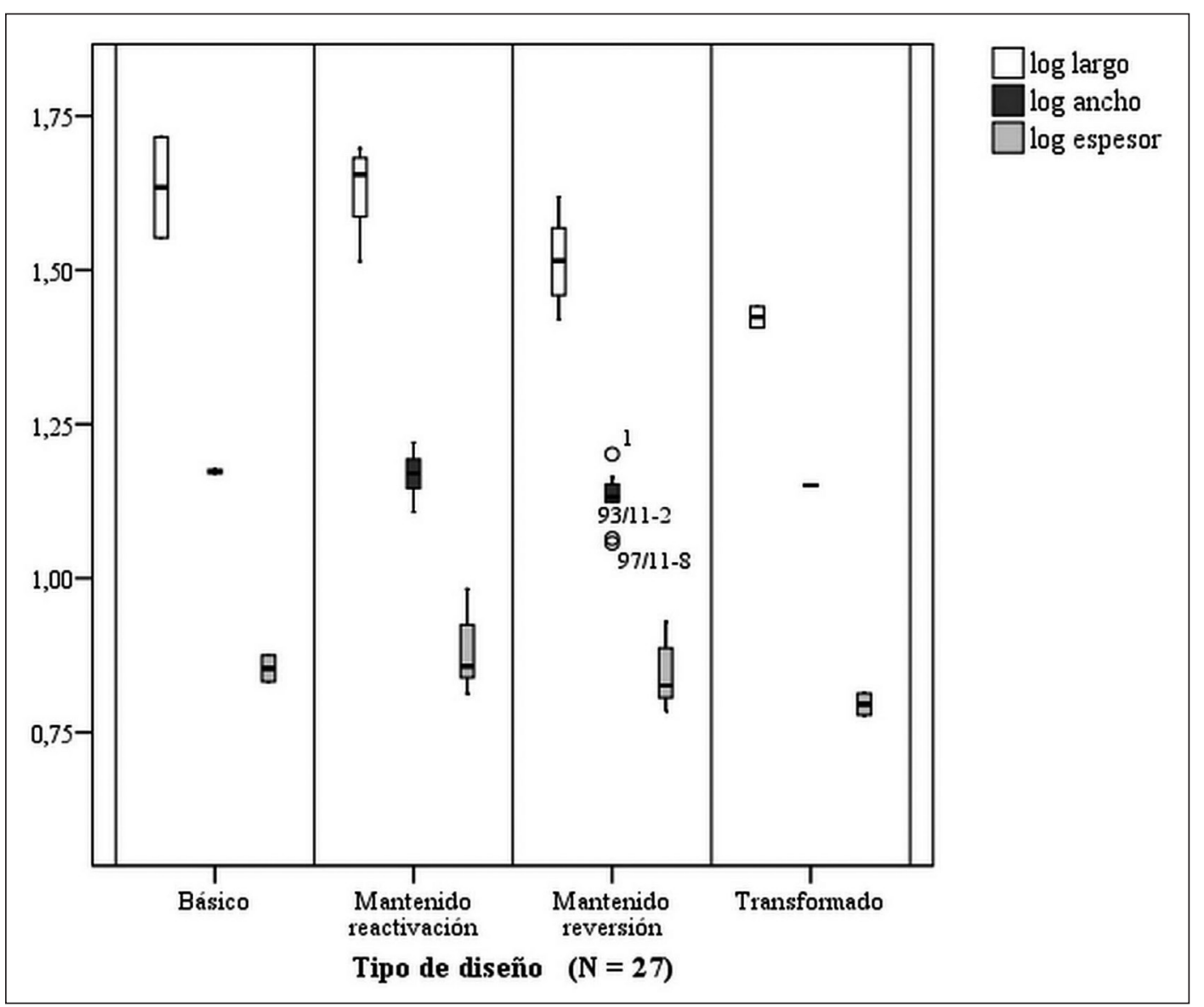

Figura 8. Diagrama de caja que muestra la dispersión de largo, ancho y espesor con datos transformados a logaritmo. 
Los resultados señalan: a) una correlación significativa de magnitud alta y negativa del largo vs. Índice de Reavivamiento. Además, la fuerza de correlación entre variables $\left(r^{2}\right)$ es media-alta con valor de o,624. Los valores indican procesos de mantenimiento en la muestra con reducción del largo de la pieza; b) correlación significativa de magnitud media y negativa del ancho vs. Índice de Reavivamiento. Sin embargo, la fuerza de correlación entre variables es baja $\left(r^{2}=0,148\right)$. Los valores dan cuenta de una tendencia no muy significativa a modificar los anchos de las piezas en el proceso de mantenimiento; c) correlación no significativa entre el espesor y el Índice de Reavivamiento. El resultado indica que no hay modificación de los espesores en el proceso de mantenimiento; d) correlación significativa de magnitud muy alta y positiva de los índices de Reavivamiento vs. Robustez, siendo la fuerza de la correlación alta $\left(r^{2}=0,693\right)$. De esto se desprende que el proceso de mantenimiento y reducción de la masa de las piezas tiende a generar piezas más robustas; e) en cuanto al largo vs. Índice de Robustez, se registra una correlación significativa de magnitud media y negativa, siendo la fuerza de la correlación baja $\left(r^{2}=\right.$ $0,248)$, mientras que no es significativa para las variables ancho y espesor. El resultado denota que únicamente la reducción del largo de la pieza está aportando a la generación de piezas más robustas.

También se nota que la dispersión de valores del Índice de Reavivamiento de los diseños mantenidos por reactivación se solapan con los básicos y los de reversión (Figura 9). Si se desglosa la muestra en función de su procedencia se ve que ese comportamiento es exclusivo de ICc7 (6:20). De hecho, en este sitio se observan valores de índices de mantenimiento por reactivación inferiores y/o iguales a los diseños básicos. Esta situación no se observa en Cam-14, donde los diseños mantenidos presentan siempre índices mayores a los diseños básicos. Desgraciadamente, los diseños básicos que componen la muestra son muy pocos para generar valores referenciales confiables. De todos modos, es posible observar una tendencia donde los valores del Índice de Reavivamiento de los diseños mantenidos por reactivación son menores a aquellos mantenidos por reversión. Es probable que en el caso de ICc7 este diseño tenga un rango de variación en largo y que la pieza en cuestión sea el límite inferior. Esto implica que los diseños básicos en su extremo superior son más grandes que el mayor largo dentro de los diseños mantenidos por reactivación. Así, en ICc7 ingresaron

\begin{tabular}{|c|c|c|c|c|c|c|}
\hline & & Largo & Ancho & Espesor & $\begin{array}{c}\text { Índice de } \\
\text { Reavivamiento }\end{array}$ & $\begin{array}{l}\text { Índice de } \\
\text { Robustez }\end{array}$ \\
\hline \multirow{3}{*}{ Largo } & Correlación de Pearson & 1 & $\left.0,545^{(* *}\right)$ & $0,701\left({ }^{* *}\right)$ & $-0,790^{(* *)}$ & $-0,498(* *)$ \\
\hline & Sig. (bilateral) & - & 0,003 & 0,000 & 0,000 & 0,008 \\
\hline & $\mathrm{N}$ & 27 & 27 & 27 & 27 & 27 \\
\hline \multirow{3}{*}{ Ancho } & Correlación de Pearson & $0,545^{(* *)}$ & 1 & 0,364 & $-0,386\left(^{*}\right)$ & 0,178 \\
\hline & Sig. (bilateral) & 0,003 & - & 0,062 & 0,047 & 0,375 \\
\hline & $\mathrm{N}$ & 27 & 27 & 27 & 27 & 27 \\
\hline \multirow{3}{*}{ Espesor } & Correlación de Pearson & $0,701(* *)$ & 0,364 & 1 & $-0,139$ & 0,108 \\
\hline & Sig. (bilateral) & 0,000 & 0,062 & - & 0,489 & 0,591 \\
\hline & $\mathrm{N}$ & 27 & 27 & 27 & 27 & 27 \\
\hline \multirow{3}{*}{$\begin{array}{l}\text { Índice de } \\
\text { Reavivamiento }\end{array}$} & Correlación de Pearson & $-0,790^{(* *)}$ & $-0,386\left(^{*}\right)$ & $-0,139$ & 1 & $0,833^{(* *)}$ \\
\hline & Sig. (bilateral) & 0,000 & 0,047 & 0,489 & - & 0,000 \\
\hline & $\mathrm{N}$ & 27 & 27 & 27 & 27 & 27 \\
\hline \multirow{3}{*}{$\begin{array}{l}\text { Índice de } \\
\text { Robustez }\end{array}$} & Correlación de Pearson & $-0,498^{(* *)}$ & 0,178 & 0,108 & $0,833^{(* *)}$ & 1 \\
\hline & Sig. (bilateral) & 0,008 & 0,375 & 0,591 & 0,000 & - \\
\hline & $\mathrm{N}$ & 27 & 27 & 27 & 27 & 27 \\
\hline
\end{tabular}

Tabla 5. Análisis de correlación ( $\mathrm{r}$ de Pearson). $\left(^{*}\right)$ : La correlación es significante al nivel o,05 (bilateral). (**): La correlación es significativa al nivel o,ol (bilateral). 


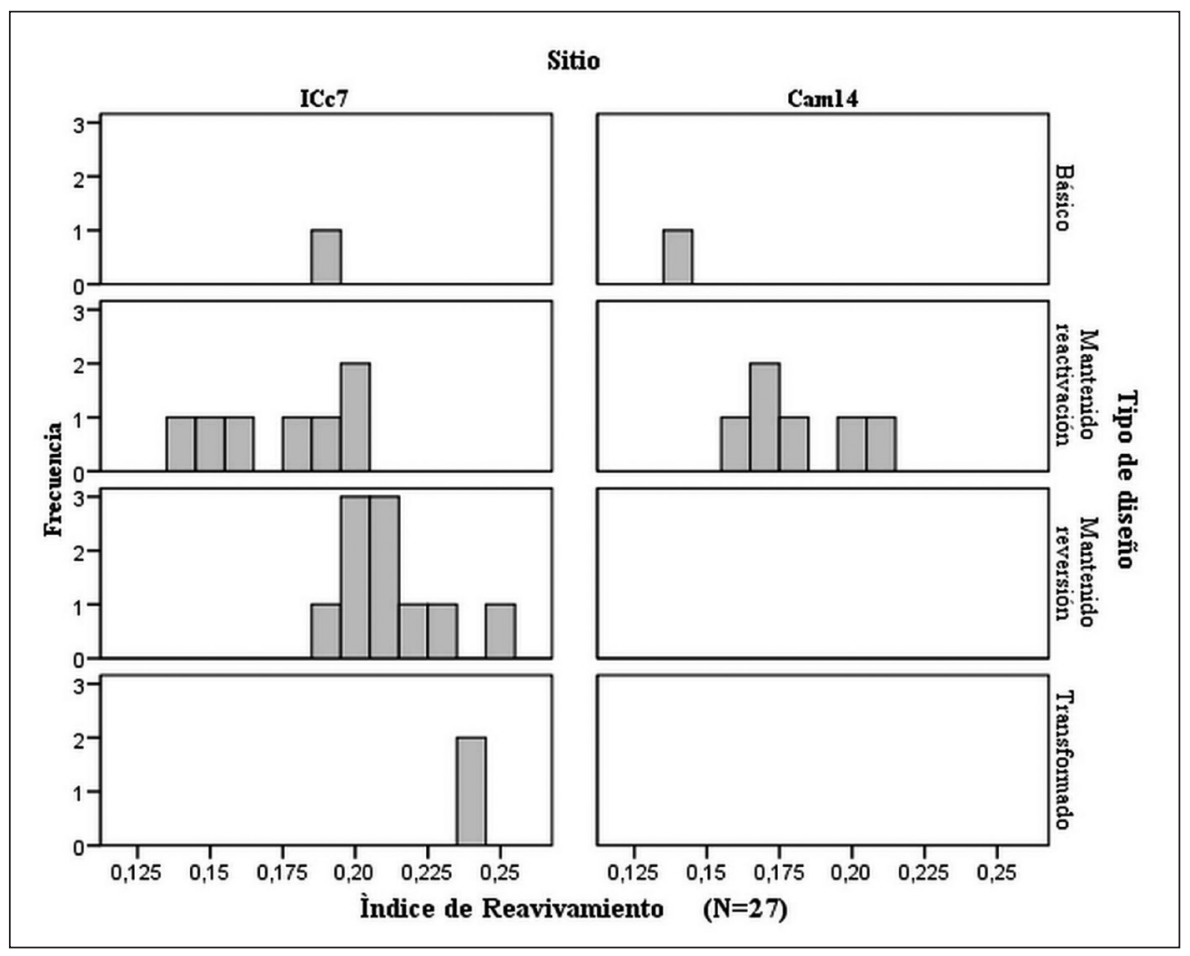

Figura 9. Histograma donde se compara el Índice de Reavivamiento entre Inca Cueva 7 y Camarones 14.

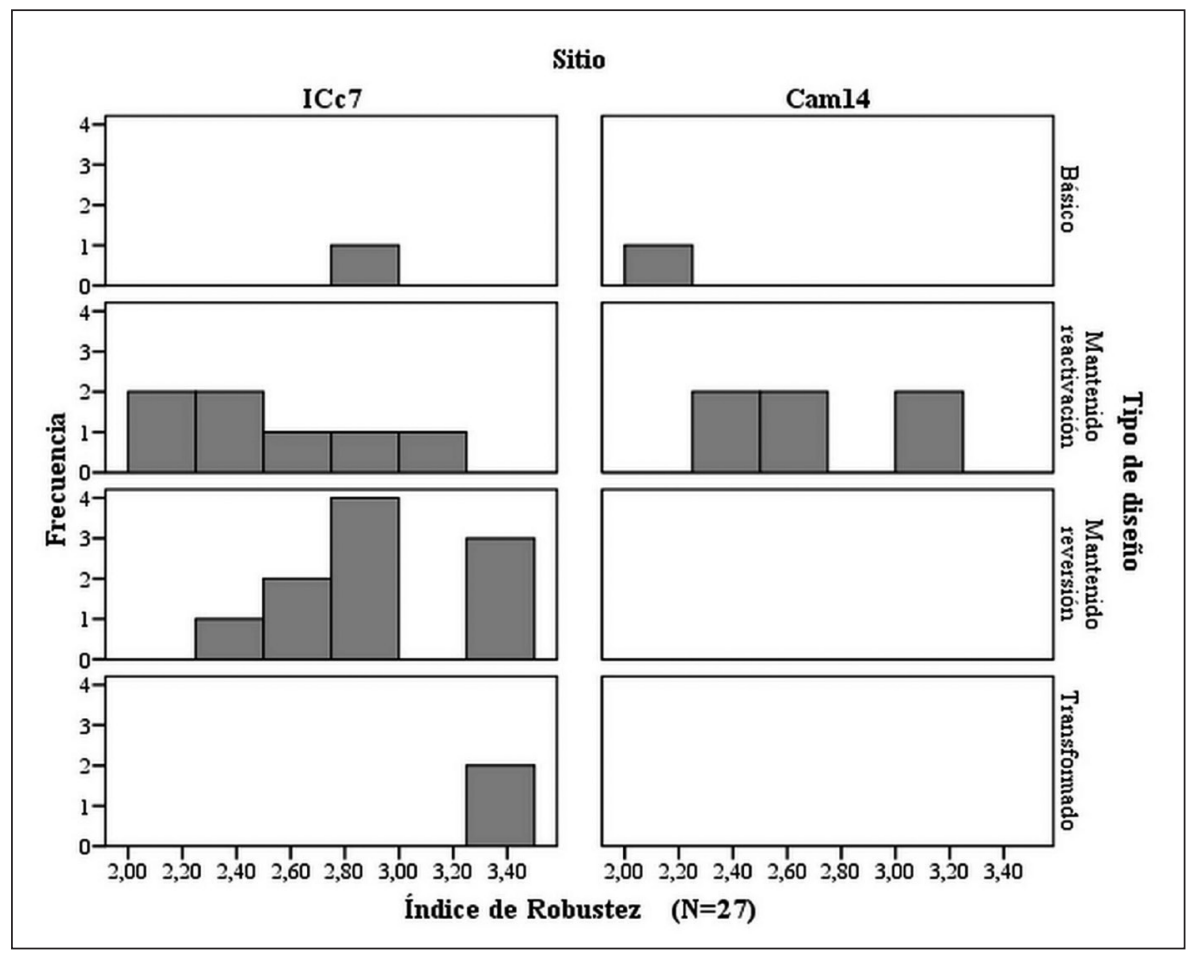

Figura 10. Histograma donde se compara el Índice de Robustez entre Inca Cueva 7 y Camarones 14. 
piezas que tenían toda una historia de vida previa, y que estaban extensamente modificadas en largo. Lo importante es que las piezas mantenidas por reactivación más largas dan una idea de los tamaños originales ausentes.

Una situación similar se observa en el caso de la robustez (Figura 10). También en ICc7 es donde los índices de los diseños mantenidos por reactivación y reversión son mayormente iguales o menores al diseño básico, con las mismas limitaciones que presenta éste por tratarse de un caso único. Sin embargo, en Cam-14, los índices de los diseños mantenidos son mayores que el diseño básico.

La Figura 11 muestra que la correlación negativa entre las variables largo e Índice de Reavivamiento tiene una fuerza alta $\left(r^{2}\right.$ de Pearson = 0,794). Sin embargo, los ejemplares de ICc7 no cumplen la expectativa esperada; es decir, que los Índices de Rejuvenecimiento marcan una proyección de diseño básico mantenido revertido, ya que los casos identificados en el gráfico y clasificados como diseños mantenidos por reactivación presentan valores menores al diseño básico. Como ya se mencionó, en el sitio esto se debería a la ausencia de piezas correspondientes a diseños básicos de mayor tamaño. La tendencia indica que la relación sí se cumple para el caso de los diseños por reversión, ya que los valores de sus largos son menores al básico, mientras que los Índices de Reavivamiento son mayores al mismo.

Sobre la base de lo observado en ICc7 es factible sostener que los diseños básicos en "mandorla" presentaban un rango de tamaño en largo, como es esperable en cualquier clase de diseño de punta de proyectil. A partir de esto se considera como largo, para discriminar la muestra, el valor medio dado por el único diseño básico (pieza 15) y el ejemplar de máximo largo con registro de mantenimiento por reactivación (pieza 4). Por lo tanto, la muestra se divide tomando como referencia un largo de 41,90 mm y no se considera el diseño básico por lo que ésta se reduce a 19 casos (sobre 20). Se aplica la prueba de $\mathrm{x}^{2}$ para ver si existen diferencias en el largo de las piezas en función del tipo de mantenimiento o transformación de las mismas; en consecuencia, se rechaza la hipótesis nula del test sosteniendo que existen diferencias en el largo en función

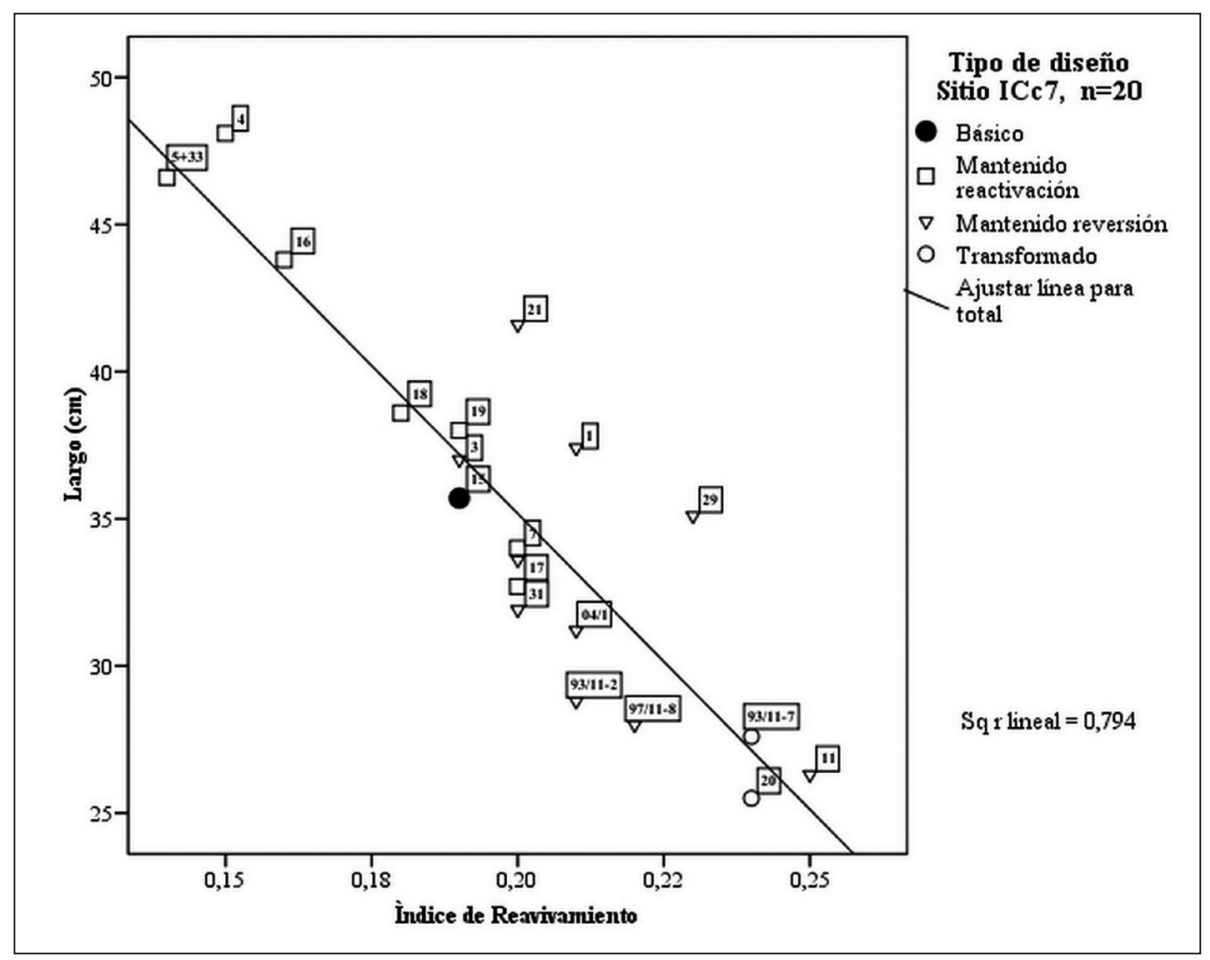

Figura 11. Correlación entre las variables Largo e Índice de Reavivamiento por tipo de diseño para Inca Cueva 7. 
del mantenimiento/transformación de las piezas $\left(\mathrm{Chi}^{2}=\right.$ 6.107, gl 2, p = 0.05) (Tablas 6 y 7 ).

\begin{tabular}{|l|c|c|c|c|c|c|}
\cline { 2 - 7 } \multicolumn{1}{c|}{} & \multicolumn{5}{c|}{ Casos } \\
\cline { 2 - 7 } \multicolumn{1}{c|}{} & \multicolumn{2}{|c|}{ Válidos } & \multicolumn{2}{c|}{ Perdidos } & \multicolumn{2}{c|}{ Total } \\
\cline { 2 - 7 } \multicolumn{1}{c|}{} & N & $\%$ & N & $\%$ & N & $\%$ \\
\hline $\begin{array}{l}\text { Segmentación } \\
\text { de la muestra en } \\
\text { largo 41,9 cm }\end{array}$ & 19 & 100 & 0 & 0 & 19 & 100 \\
\hline
\end{tabular}

Tabla 6. Resumen del procesamiento de los casos.

\begin{tabular}{|l|c|c|c|}
\cline { 2 - 4 } \multicolumn{1}{c|}{} & Valor & gl & $\begin{array}{c}\text { Sig.asintótica } \\
\text { (bilateral) }\end{array}$ \\
\hline $\mathrm{Chi}^{2}$ & $\left.6,107^{*}\right)$ & 2 & 0,047 \\
\hline Razón de verosimilitudes & 7,013 & 2 & 0,030 \\
\hline Asociación lineal por lineal & 4,531 & 1 & 0,033 \\
\hline $\mathrm{N}^{\circ}$ de casos válidos & 19 & & \\
\hline
\end{tabular}

Tabla 7. Pruebas de chi ${ }^{2} .\left(^{*}\right) 4$ casillas $(66,7 \%)$ tienen una frecuencia esperada inferior a 5 .

La frecuencia mínima esperada es 0,32.

\section{Intermediarios de astil, ataduras de tendones y sectores basales de las piezas líticas}

En ICc7 se recuperaron tres intermediarios para puntas de proyectil confeccionados sobre caña maciza (Chusquea lorentziana). El primero, una pieza completa no decorada proviene de la excavación de 1972; el segundo, también recuperado en dicha excavación, consiste en un intermediario decorado que presenta una fractura longitudinal; el tercero proviene de una recolección realizada en 2004 de materiales dispersos en el talud, en inmediata proximidad a la entrada de la cueva (Figura 12).

La pieza completa evidencia en su zona proximal un nudo original de la caña que fue oportunamente rebajado. Tiene una longitud de $89 \mathrm{~mm}$ y un diámetro máximo de $13 \mathrm{~mm}$ (Figura 12a). El extremo distal ha sido ahuecado produciendo una cavidad de $9 \mathrm{~mm}$ de diámetro y de $13 \mathrm{~mm}$ de profundidad, con escotaduras opuestas, que continúan en los laterales de la caña como dos ranuras in- cisas trazadas en puntos extremos del diámetro de la pieza. En la parte externa de la concavidad uno de los bordes presenta restos de adhesivo o una sustancia agregada de color café oscuro. Entre el inicio de las ranuras y el final de la escotadura hay una atadura (embarrilado) con cinco pasadas de tendón, firmemente ajustado. Algunas de las puntas en "mandorla" recuperadas en el sitio calzan perfectamente en la cavidad y la presencia de ese adhesivo en el borde distal del intermediario coincide con la presencia mayoritaria del adhesivo en el sector medial-distal de las puntas de proyectil.

La segunda pieza presenta una fractura longitudinal en toda su extensión (Figura 12b). Es pertinente reproducir aquí lo observado por Martínez en este fragmento:

"Está fracturado longitudinalmente y se observa que la cara interna tiene sectores alisados y brillosos, como si hubiera estado en contacto con el fragmento faltante. Estas superficies podrían haber sido 'pulidas' por el rozamiento de una cara con la otra mitad del intermediario. La cara externa en un extremo (probablemente proximal) está rebajada o aguzada, pudiendo ser el área de inserción del intermediario en aloún tipo de enchufe tipo 'hembra'" (1997: 79).

En cuanto a sus dimensiones, tiene $105,30 \mathrm{~mm}$ de largo -fracturado-, 10,67 mm de diámetro promedio y 9,96 mm de diámetro en la zona de inserción (Martínez 1997 Ms). La tercera y última pieza es un fragmento distal con una doble fractura, longitudinal y transversal, en el que aún se observa la cavidad de sujeción de la punta lítica.

En este marco, se resaltan los resultados obtenidos por Aschero y Martínez (2003) mediante la realización de una prueba experimental donde se replicaron los diseños en "mandorla" y los intermediarios de ICc7, y se evaluó el funcionamiento del sistema de arma (propulsor) efectuando una serie de lanzamientos y observando los efectos de los impactos sobre las distintas partes del sistema. Así, destaca la tendencia de los intermediarios a fracturarse longitudinalmente, siguiendo el sentido de la acanaladura de inserción de las puntas de proyectil. Resultados coincidentes fueron obtenidos por Newcomer, al replicar diseños en "mandorla" de Telarmachay - con la salvedad de que experimentó con arco-, como puede apreciarse en Lavallée y colaboradores (1995: 177, lám. 14). 


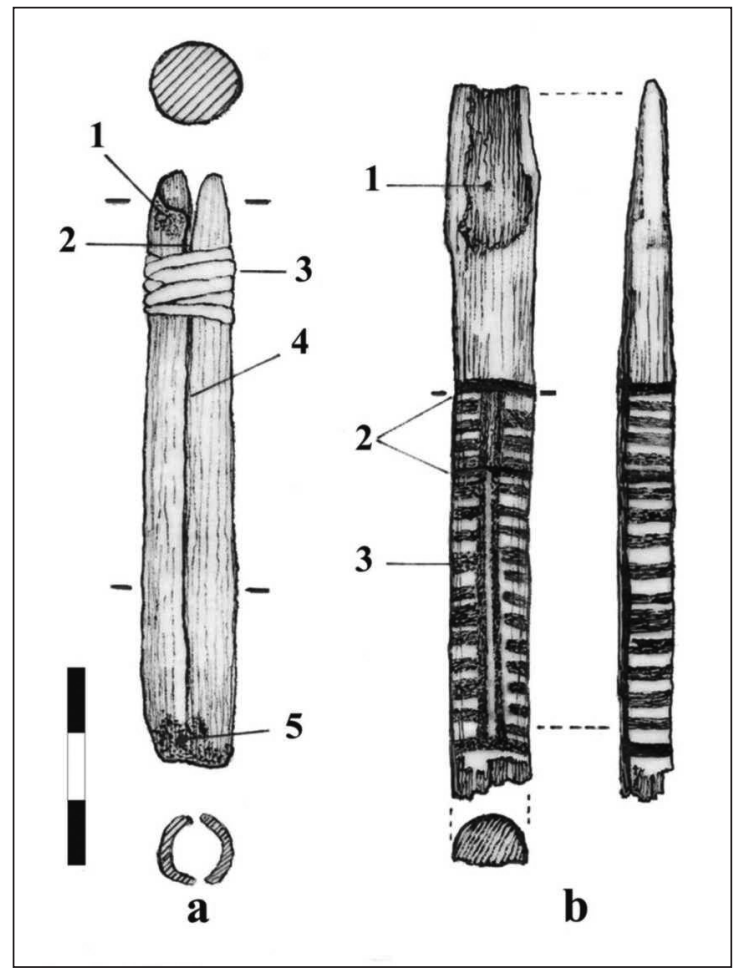

Figura 12. a) Intermediario completo en caña maciza: 1. Restos de pegamento en el exterior e interior de la cavidad de encastre; 2. Ranura de la cavidad de encastre; 3 . Atadura con tendón; 4. Incisión longitudinal para guiar la fractura; 5. Sector basal rebajado y "machacado". b) Fragmento longitudinal de intermediario con fractura guiada; 1 . Zona rebajada del nudo de la caña maciza;

2. Trazos de pintura negra; 3 . Trazos de pintura roja.

Entonces, la ranura longitudinal observada en las piezas arqueológicas debía operar como una marca-guía en el caso de un impacto fuerte que generara la fractura del intermediario desde la base de la punta. La ranura direccionaría la fractura produciendo dos partes simétricas que podrían reutilizarse uniéndolas mediante una nueva atadura en la parte mesial o meso-proximal. Precisamente, los dos fragmentos del intermediario presentan un plano de fractura longitudinal que coincidiría con la disposición de las ranuras formatizadas. Este sistema de "guiar fracturas previsibles" implica una maximización en el uso de los intermediarios y una notable economía de esfuerzos en el mantenimiento de los mismos. ${ }^{4} \mathrm{La}$ incisión longitudinal de éste, en el caso

4 Ver discusión en Aschero y Martínez (2003). del hundimiento de la punta y la rajadura de la caña, actuaría como una fisura guía de la rajadura, orientándola y haciendo que el intermediario se parta en partes iguales. En estos casos una atadura suplementaria en su sector proximal bastaría para ponerlo en uso nuevamente. Estas características del intermediario se pueden ver directamente en relación con la reversión de los diseños de puntas en "mandorla".

De la observación de ataduras independientes en algunas de las puntas de proyectil recuperadas (tres o más pasadas de tiras de tendón), ubicadas hacia el centro de la pieza, se infiere que la porción basal de la punta era insertada en la cavidad del intermediario a presión, y que esta atadura central en el borde distal del intermediario impedía el retroceso de la punta en caso de impactos fuertes. El adhesivo era colocado antes de insertar la punta en el intermediario y cubría todo el sector basal.

La atadura de tendón en el centro de la pieza también sirve para suplementar el espesor/ancho de la punta de proyectil en el extremo del intermediario, evitando su movimiento y/o para mitigar o evitar el hundimiento de la punta en el intermediario. Tres piezas poseen este dispositivo: la pieza 19 presenta una atadura de tendón que coincide con el cuello del sector basal; las piezas 17 y 18 , además de la vena, llevan un refuerzo de tendón, posiblemente asociado a un cambio de intermediario (ver Figura 4).

En estas puntas de proyectil el cuello del sector basal se define por un tendón in situ, que coincide con las evidencias morfológicas que permiten discriminar el limbo del área de enastilado. Asimismo, en otras piezas, en el lugar donde están las ataduras se aprecia una línea de sustancia adherida de color café amarillento, que coincide con el inicio de los bordes del sector basal. Ejemplos de esto son las piezas 4 y 21. Por otra parte, en el ejemplar 20, el límite se establece observando donde termina la distribución del adhesivo en el sector basal.

Las puntas de proyectil en "mandorla" de ICc7 presentan distintas formas de preparación de los sectores basales, sean bordes y/o bases, con adecuaciones de forma o espesor para posibilitar el enastilado. La mayoría presenta un estrechamiento mínimo en ambos bordes que permite discriminar al limbo del sector basal. Así, aunque los 
bordes son convexos en toda su extensión, se diferencian por el grado de convexidad, es decir, bordes de limbo más convexos y bordes de sector basal menos convexos. Dicha inflexión es el resultado tanto de la realización premeditada de series de lascados (que pueden ser alternos o no), como de la acción de compresión del tendón sobre los bordes, pudiendo presentarse una u otra situación o una combinación de ambas. De esta forma, se registra una clara distinción entre el limbo y el sector basal en norma frontal y lateral. En la primera, se observa un ligero estrechamiento, mientras que en la segunda, dicho estrechamiento se ve correspondido con un cambio en la orientación de la arista en ambos bordes.

A su vez, las bases o las porciones proximales de los bordes en algunas piezas presentan uno o más lascados que actúan rebajando el espesor en el centro de una de las caras, posibilitando una adecuada inserción en el intermediario. En norma lateral estas acciones resultan en un bisel levemente asimétrico en la porción del sector basal afectado por este procedimiento y en un punto de quiebre con cambio de ángulo, aproximadamente en la mitad del mismo, en la porción no afectada.

\section{* Consideraciones finales}

La información de las puntas de proyectil es coincidente con los datos del resto de las tecno-facturas del sitio ICc7, respecto del uso intensivo al que ha sido sometido el conjunto de objetos (Aguerre et al. 1973; Aschero y Yacobaccio 1998-99; Aschero 2010). Las evidencias tecnotipológicas de las puntas de proyectil en "mandorla" son contundentes en este sentido, poseen historias de vida largas y complejas, lo que se ve reforzado al considerar las sustancias adheridas, ataduras y refuerzos de tendón.

Las piezas de ICc7, más allá de las similitudes de diseño con las de Cam-14, se diferencian de estas últimas en las formas de prolongación de la vida útil, ya que no hay reversión en las del norte de Chile. Las razones de esto son múltiples. Por ejemplo, configuraciones distintas de los sistemas de armas (formas de enastilado) que hacen proclive al diseño ser mantenido por reversión o no; presas diferentes que llevan a condiciones de captura distintas (terrestres o marinas) con tasas de fractura diferenciales, entre otras.
Cabe destacar que en el caso de la quebrada de Inca Cueva, las cuarcitas y los sílices son de origen local; las fuentes se encuentran muy cerca de ICc7, y también corresponden a las dos clases de rocas mayoritarias en la confección de las puntas de proyectil en "mandorla" (Ratto 1991). Si a esto se suma que la calidad de dichas rocas para la talla es de buena a muy buena, ni su disponibilidad ni su calidad habrían incidido en los procesos de extensión de vida útil. Al respecto, se considera que fue el propio diseño de la punta de proyectil lo que se quiso conservar, aunque dicha elección estaba vinculada también con la elaboración de intermediarios factibles de ser reutilizados.

Las diferencias que hemos señalado en las maneras de mantener las puntas de proyectil son interesantes de abordar ya que reflejan formas distintas de hacer las cosas en las cuales no hay restricciones de índole técnico para que no se dé. Se parte de la base de que en todo grupo social hay ciertas formas "adecuadas" o "correctas" de hacer las cosas, las cuales se encuentran mediadas socialmente (Lemonnier 1993). La presencia o no de reversión en los contextos abordados se vincula con esto, aunque es necesario profundizar en el estudio de los procesos de mantenimiento en sitios sincrónicos procedentes de distintas áreas de la porción meridional de los Andes Centro Sur para poder realizar mayores aseveraciones.

Un aspecto que debe ser destacado es que en el conjunto de puntas de proyectil de ICc7 no hay piezas lanceoladas como diseños básicos. Esto es significativo ya que recurrentemente se ha tomado a este sitio como punto de referencia para dar cuenta de las tecnologías de proyectil de fines del Holoceno Medio e inicios del Holoceno Tardío de la Puna Septentrional argentina. En realidad, el componente lanceolado en ICc7 es prácticamente inexistente, limitándose a un solo caso, resultado de la transformación a partir de una pieza en "mandorla". Esto lleva a discutir la idea de la importancia de los diseños lanceolados en la Puna de Jujuy, lo que se ve corroborado con la información disponible de otros sitios del área.

Así, respecto a la distribución espacial de este diseño de punta de proyectil, destaca su recurrencia en sitios de la Puna Septentrional argentina con fechas entre ca. 4500 y 2500 años AP (ver Figura 1). Las descripciones morfológicas de forma geométrica del contorno realizadas 
por distintos investigadores y la observación de piezas a partir de fotos y gráficos publicados, posibilita obtener un panorama general en este sentido. De esta forma, se ha identificado al diseño en "mandorla" en distintos sitios de la zona de El Aguilar, inmediata a la quebrada de Inca Cueva, a saber: Tomayoc, 4250 \pm 50 AP (Lavallée et al. 1997); Potrero de Caballo Muerto, $3590 \pm 90$ AP y 3410 70 AP (Fernández 1996); Peña Aujero, $3450 \pm 50$ AP (Fernández Distel et al. 1981); Cueva de El Portillo, $3830 \pm 185$ AP y $3000 \pm 160$ AP (Fernández 1997) y Cueva de Cristóbal, $2860 \pm 160$ AP, $2630 \pm 140$ AP, $2600 \pm 120$ AP y $2530 \pm 100$ AP (Fernández 198889; Hocsman et al. 2010). Diseños de este tipo se han recuperado también en sectores al oeste de Inca Cueva y El Aguilar, como Morro Blanco/El Pasaje (Guayatayoc), 3995 \pm 75 AP (Fernández 1988-89; Fernández Distel 2007); Alero Unquillar (Susques), $3530 \pm 70 \mathrm{AP}$, $3510 \pm 110$ AP y $3050 \pm 60$ AP (Yacobaccio et al. 2000); Alero Caído I (Coranzulí), $3200 \pm 70$ AP, 2930 \pm 70 AP y $2670 \pm 50$ AP (Aschero 2010) y Cueva QII de Quichagua - sin fechado- (Fernández Distel 1983). En la mayoría de los sitios este diseño se encuentra asociado a una serie de puntas de proyectil apedunculadas y pedunculadas, en contextos de gran variabilidad tipológica, de la cual no hay un panorama muy preciso. Al respecto, se ha visto la alta selectividad que muestra el conjunto de tecnofacturas recuperado en ICc7 (Aschero 2010), lo cual se ve replicado al considerar el diseño en "mandorla", ya que es evidente que éste ha estado sujeto a tal selección frente a otros diseños posibles (p.e., ejemplar pedunculado tipo Punta del Diablo sensu Fernández [1971] recuperado en ICc7, u otros que, sin estar presentes aquí, han sido hallados en sitios relativamente cercanos a El Aguilar, como aquel pedunculado Morro Blanco [Fernández 1983-84]). En consecuencia, es pertinente explorar esta variabilidad, considerando diversas variables, ya sea económicas, funcionales, sociales o de otro tipo.

Resulta importante precisar la cronología de este diseño, ya que las fechas disponibles en ciertos casos son problemáticas y, en general, fueron realizadas hace más de 20 años en diferentes laboratorios, bajo diferentes métodos y empleando distintos materiales. Más allá de todo esto, al considerar los contextos de recuperación, destaca el hecho de que estas puntas de proyectil acompañaron el proceso de cambio desde una economía basada en la caza a otra sustentada en la producción de alimentos ocurrido en Puna de Jujuy, siendo características de componentes cazadores recolectores, cazadores recolectores transicionales y agropastoriles tempranos.

Ahora bien, la distribución de los diseños en "mandorla" está presente aunque en muy baja proporción en la Puna chilena, donde es claramente dominante el patrón lanceolado. Tal es el caso de los sitios Tulan $52,4580 \pm 90$ AP a $3860 \pm 60$ AP y Puripica 1, 4815 \pm 70 AP a 4050 95 AP (Núñez 1981; Núñez et al. 2006). Por otra parte, en la Puna Meridional argentina, más específicamente en la Puna de Catamarca, es significativo que este diseño esté ausente en las regiones de Chaschuil (Ratto 2006) y Antofalla (Moreno 2010), mientras que en Antofagasta de la Sierra existe una sola de estas piezas sobre más de 100 puntas de proyectil (Hocsman 2006, 2010). En estas regiones se halla más bien una importante variedad de diseños pedunculados y apedunculados, destacando dentro de estos últimos los lanceolados.

Es así que la alta recurrencia de las piezas en "mandorla" en las localidades de Inca Cueva/El Aguilar y Coranzulí y Susques, entre otras, y su ausencia en la Puna catamarqueña, sugiere que este diseño (en sus tipos básicos, mantenidos y transformados) puede ser considerado un tipo diacrítico en las interacciones sociales que ocurren en la Puna argentina. Su presencia en áreas vecinas como el Salar de Atacama, en lapsos relativamente sincrónicos (ca. $4000 \mathrm{AP}$ ), también puede ser tomada como posible indicador de interacciones.

Agradecimientos Este trabajo se desarrolló en el marco de los Proyectos PIP-CONICET 6398 y PICT 38127 , dirigidos por Carlos Aschero; PICT 26040, dirigido por Nora Franco y PIP-CONICET 0461, PICT 1567 y CIUNT 26/G424, dirigidos por Salomon Hocsman. Los autores agradecen a Jorge Funes por los dibujos de las piezas y a Aldo Agustín Gerónimo por el tratamiento digital de las imágenes. 


\section{* Referencias citadas}

AGUERRE, A., A. FERNÁNDEZ DISTEL y C. ASCHERO, 1973. Hallazgo de un sitio acerámico en la quebrada de Inca Cueva (provincia de Jujuy). Relaciones de la Sociedad Argentina de Antropología 7: 197-235.

1975. Comentarios sobre nuevas fechas en la cronología arqueológica precerámica de la provincia de Jujuy. Relaciones de la Sociedad Argentina de Antropología 9: 211-214.

ASCHERO, C., 1975 Ms. Ensayo para una clasificación morfológica de artefactos líticos aplicada a estudios tipológicos comparativos. Informe al CONICET, Buenos Aires.

1983 Ms. Ensayo para una clasificación morfológica de artefactos líticos aplicada a estudios tipológicos comparativos. Apéndices A-C. Cátedra de Ergología y Tecnología, Facultad de Filosofía y Letras, Universidad de Buenos Aires, Buenos Aires.

1988. De punta a punta: Producción, mantenimiento y diseño en puntas de proyectil precerámicas de la Puna argentina. Actas del IX Congreso Nacional de Arqueología Argentina, pp. 219-229, Buenos Aires.

2010. Arqueología de Puna y Patagonia Centro Meridional: Comentarios generales y aporte al estudio de los cazadores recolectores puneños en los proyectos dirigidos desde el IAM (1991-2009). En Rastros en el camino... Trayectos e identidades de una institución. Homenaje a los 80 años del IAM-UNT, P. Arenas, C. Aschero y C. Taboada (Eds.), pp. 257-293. EDUNT Editorial, San Miguel de Tucumán.

ASCHERO, C. y S. HOCSMAN, 2004. Revisando cuestiones tipológicas en torno a la clasificación de artefactos bifaciales. En Temas de arqueología. Análisis lítico, M. Ramos, A. Acosta y D. Loponte (Comps.), pp. 7-25. Universidad Nacional de Luján, Luján.

ASCHERO, C. y J. MARTÍNEZ, 2003. Proyectiles experimentales: Inca Cueva 7 como caso de estudio. Cuadernos de la Facultad de Humanidades y Ciencias Sociales 20: 351-364.

ASCHERO, C. y H. YACOBACCIO, 1998-99. 20 años después: Inca Cueva 7 reinterpretado. Cuadernos del Instituto Nacional de Antropología y Pensamiento Latinoamericano 18: 7-18.

BORDES, F., 1961. Typologie du Paléolithique Ancien et Moyen. Delmas, Bordeaux.

BRÉZILLON, M., 1983. La dénomination des objets de pierre taillée. Centre National de la Recherche Scientifique, París.
CARDILLO, M., 2005. Explorando la variación en las morfologías líticas a partir de la técnica de análisis de contornos. El caso de las puntas de proyectil del Holoceno Medio-Tardío de la Puna de Salta (San Antonio de los Cobres, Argentina). Revista Werkén 7: 77-88.

CHEYNIER, A., 1955. Feuilles de laurier à cran. Bulletin de la Société Préhistorique Française 52: 284-286.

DEMARS, P. y P. LAURENT, 1992. Types d'outils lithiques du Paléolithique Supérieur en Europe. Centre National de la Recherche Scientifique, París.

DE SOUZA, P., 2004a. Tecnologías de proyectil durante los períodos Arcaico y Formativo en el Loa Superior (norte de Chile): A partir del análisis de puntas líticas. Chungara, Revista de Antropología Chilena 36: 61-76.

2004b. Cazadores recolectores del Arcaico Temprano y Medio en la cuenca superior del río Loa: Sitios, conjuntos líticos y sistemas de asentamiento. Estudios Atacameños 27: 7-43.

2006. Los sistemas de proyectiles durante el proceso Arcaico Tardío-Formativo Temprano de la Puna de Atacama: Una aproximación desde el análisis de las puntas de proyectil de quebrada Tulán. Tesis para optar al grado de magíster en Antropología, Universidad de Tarapacá y Universidad Católica del Norte, San Pedro de Atacama.

FERNÁNDEZ, J., 1968. Asentamiento humano precerámico con molinos en la cuenca de Guayatayok (Puna de Jujuy). Etnia 8: 21-27.

1971. La Edad de la Piedra en la Puna de Atacama. Una investigación regional y cronológica; una aportación de la ciencia geográfica a la solución del problema vinculado a la temprana instalación humana en Sudamérica. Revista del Instituto de Antropología 1 .

1983-84. Río Grande. Exploración de un centro precerámico en las altas montañas de Jujuy, Argentina. Ampurias 45-46: 54-83.

1988-89. Ocupaciones alfareras (2860 \pm 160 años AP) en la cueva de Cristóbal, Puna de Jujuy, Argentina. Relaciones de la Sociedad Argentina de Antropología 17 (2): 139-178.

1996. Potrero de Caballo Muerto: Aspectos arqueológicos, cronológicos y paleoambientales del Precerámico Tardío en el ecosistema hidrófilo de las vegas puneñas. Revista del Museo de Historia Natural de San Rafael 24 (1-4): 23-51. 
1997. Arqueología de la Cueva de El Portillo, departamento Humahuaca, provincia de Jujuy. Avances en Arqueología 3: 41-69.

FERNÁNDEZ DISTEL, A., 1983. La Cueva QII de Quichagua y su área (departamento de Cochinoca, Jujuy, Argentina). Scripta Ethnologica 2: 29-37.

2007. El yacimiento de Guayatayoc (Jujuy, Argentina): Sus materiales líticos y un fechado de radiocarbono inédito. Cuadernos de la Facultad de Humanidades y Ciencias Sociales 32: 151-166.

FERNÁNDEZ DiSTEL, A., M. I. HERNÁNDEZ LLOSAS, M. CASIRAGHI y B. VENTURA, 1981. Arqueología de una quebrada transversal al valle de Humahuaca: Coraya. Arte rupestre y fechado radiocarbónico de la Cueva Peña Aujero. Publicaciones del Instituto de Antropología 36: 23-45.

HOCSMAN, S., 2006. Producción lítica, variabilidad y cambio en Antofagasta de la Sierra, ca. 5500-1500 AP. Tesis doctoral en Ciencias Naturales. Facultad de Ciencias Naturales y Museo, Universidad Nacional de La Plata, La Plata.

2010. Cambios en las puntas de proyectil durante la transición de cazadores recolectores a sociedades agropastoriles en Antofagasta de la Sierra (Puna argentina). Arqueología 16:59-86.

HOCSMAN, S., A. CALISAYA, A. GERÓNIMOy R. PICCÓN FIGUEROA, 2010. Relevamiento y excavaciones sistemáticas en Cueva de Cristóbal (El Aguilar, Puna de Jujuy): Resultados preliminares. En Arqueología Argentina en el Bicentenario de la Revolución de Mayo. Actas del XVII Congreso Nacional de Arqueología Argentina. R. Bárcena y H. Chiavazza (Eds.), pp. 1569-1571. Universidad Nacional de Cuyo, CONICET, Mendoza.

IRIARTE, J., 1995. Afinando la puntería: Tamaño, forma y rejuvenecimiento de las puntas de proyectil de Uruguay. Actas del VIII Congreso Nacional de Arqueología Uruguaya, M. Consens, J. López Mazz y C. Curbelo (Eds.), pp. 142-151. Surcos, Montevideo.

KNETCH, H., 1997. Projectile points of bone, antler and stone. Experimental explorations of manufacture and use. En Projectile technology, H. Knecht (Ed.), pp. 191-212. Plenum Press, Nueva York.

KLINK, C. y M. ALDENDERFER, 2005. A projectile point chronology for the South-Central Andean highlands. En Advances in Titicaca Basin Archaeology vol. 1, C. Stanish, A. Cohen y M. Aldenderfer (Eds.), pp. 25-54. Cotsen Institute of Archaeology at UCLA, Los Angeles.

LAVALLÉE, D., M. JULIEN, J. WHEELER y C. KARLIN, 1995. Telarmachay. Cazadores y pastores de los Andes. Instituto Francés de Estudios Andinos, Lima.
LAVALLÉE, D., M. JULIEN, C. KARLIN, L. GARCÍA, D. POZZIESCOT y M. FONTUGNE, 1997. Entre desierto y quebrada: Tomayoc, un alero de la Puna.Avances en Arqueología 3: 9-39.

LEMONNIER, P., 1993. Introduction. En Technological choices. Transformation in material cultures since the Neolithic, P. Lemonnier (Ed.), pp. 1-35. Routledge, Londres y Nueva York.

MARTÍNEZ, J., 1997 Ms. Estrategias y técnicas de caza. Análisis tipológico-tecnológico de proyectiles arqueológicos. Manuscrito en poder del autor.

2003. Ocupaciones humanas tempranas y tecnología de caza en la microrregión de Antofagasta de la Sierra (10000-7000 AP). Tesis doctoral, Facultad de Ciencias Naturales e Instituto Miguel Lillo, Universidad Nacional del Tucumán, Tucumán.

2007. Ocupaciones humanas tempranas y tecnología de caza en Antofagasta de la Sierra, Puna Meridional argentina (100007000 AP). Cazadores Recolectores del Cono Sur. Revista de Arqueología 2: 129-150.

MORENO, E., 2010. Arqueología de la caza de vicuñas en el área del Salar de Antofalla, Puna de Atacama. Una aproximación desde la arqueología del paisaje. Tesis doctoral, Facultad de Ciencias Naturales y Museo, Universidad Nacional de La Plata, La Plata.

MUSCIO, H., 2001 Ms. Una revisión crítica del Arcaico Surandino. Cátedra de Fundamentos de Prehistoria. Facultad de Filosofía y Letras, Universidad de Buenos Aires.

NIEMEYER, H. y V. SCHIAPPACASSE, 1977. Investigación de un sitio temprano de cazadores recolectores arcaicos en la desembocadura del valle de Camarones (I región de Chile). Actas del VII Congreso de Arqueología de Chile, vol. 1, pp. 115-118. Ediciones Kultrún, Santiago.

NÚÑEZ, L., 1981. Asentamientos de cazadores recolectores tardíos de la Puna de Atacama: Hacia el sedentarismo. Chungara 8: 137168.

1992. Ocupación arcaica en la Puna de Atacama: Secuencia, movilidad y cambio. En Prehistoria sudamericana. Nuevas perspectivas, B. Meggers (Ed.), pp. 283-307. Taraxacum, Washington D.C.

NÚÑEZ, L., M. GROSJEAN e I. CARTAJENA, 2005. Ocupaciones humanas y paleoambientes en la Puna de Atacama. Universidad Católica del Norte y Taraxacum, San Pedro de Atacama.

NÚÑEZ, L., I. CARTAGENA, C. CARRASCO, P. DE SOUZAy M. GROSJEAN, 2006. Emergencia de comunidades pastoralistas formativas en el sureste de la Puna de Atacama. Estudios Atacameños 32: 93-117. 
ORQUERA, L. y E. PIANA, 1986. Normas para la descripción de objetos arqueológicos de piedra tallada. Publicación especial, CADIC, Ushuaia.

RATTO, N. 1991. Elección de rocas y diseño de artefactos: Propiedades físico-mecánicas de las materias primas líticas del sitio Inca Cueva c-4 (Jujuy, Argentina). XI Congreso Nacional de Arqueología Chilena vol. 2, pp. 121-137. Museo Nacional de Historia Natural, Sociedad Chilena de Arqueología, Santiago.

2006. El Arcaico y Formativo en la puna de Chaschuil a través del diseño de las puntas líticas (departamento de Tinogasta, Catamarca). Cazadores Recolectores del Cono Sur. Revista de Arqueología 1: 93-109.

RICK, J., 1980. Prehistoric hunters of the High Andes. Academic Press, Nueva York.
SCHEINSOHN, V., 1997. Explotación de materias primas óseas en la Isla Grande de Tierra del Fuego. Tesis doctoral, Facultad de Filosofía y Letras, Universidad de Buenos Aires, Buenos Aires.

SCHIAPPACASSE, V. y H. NIEMEYER, 1984. Descripción y análisis interpretativo de un sitio Arcaico Temprano en la quebrada de Camarones. Publicación Ocasional del Museo Nacional de Historia Natural 14.

TOWNER, R. y M. WARBURTON, 1990. Projectile point rejuvenation: A technological analysis. Journal of Field Archaeology 17: 311-321.

YACOBACCIO, H., M. LAZZARI, A. GURAIEB y G. IBÁÑEZ, 2000. Los cazadores en el borde oriental de Atacama (Susques, Jujuy). Arqueología 10: 11-38. 